\title{
1 Effect of habitat spatiotemporal structure on collembolan diversity
}

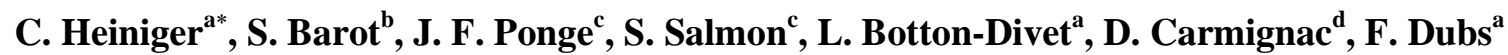

${ }^{\text {a }}$ IRD, UMR BIOEMCO, Centre France Nord, 93143 Bondy, France

${ }^{\mathrm{b}}$ IRD, UMR BIOEMCO, ENS. 75006 Paris, France

${ }^{\mathrm{c}}$ MNHN, UMR 7179, 91800 Brunoy, France

\section{${ }^{\mathrm{d}}$ ENS, UMR BIOEMCO, ENS. 75006 Paris, France}

Key words: Landscape structure and dynamics, collembolan diversity, colonization credit, patch age, patch isolation, forest vs. agriculture.

\section{ABSTRACT}

Landscape fragmentation is a major threat to biodiversity. It results in the transformation of continuous (hence large) habitat patches into isolated (hence smaller) patches, embedded in a matrix of another habitat type. Many populations are harmed by fragmentation because remnant patches do not fulfil their ecological and demographic requirements. In turn, this leads to a loss of biodiversity, especially if species have poor dispersal abilities. Moreover, landscape fragmentation is a dynamic process in which patches can be converted from one type of habitat to another. A recently created habitat might suffer from a reduced biodiversity because of the absence of adapted species that need a certain amount of time to colonize the new patch (e.g. direct metapopulation effect). Thus landscape dynamics leads to complex habitat spatiotemporal structure, in which each patch is more or less continuous in space and time. In this study, we define habitat spatial structure as the degree to which a habitat is isolated from another habitat of the same kind and temporal structure as the time since the habitat is in place. Patches can also display reduced biodiversity because their spatial or temporal structures are correlated with habitat quality (e.g. indirect effects). We discriminated direct metacommunity effects from indirect (habitat quality) effects of the spatiotemporal structure of habitats on biodiversity using Collembola as a model. We tested the relative importance of spatial and temporal

\footnotetext{
* Corresponding author. Tel. : + 33 (0) 642135945 ; fax +33 (0) 148025970

E-mail adress : charlene.heiniger@ird.fr (C. Heiniger).
} 
structure of habitats for collembolan diversity, taking soil properties into account. In an agroforested

landscape, we set up a sampling design comprised of two types of habitats (agriculture vs forest), a gradient of habitat isolation (three isolation classes) and two contrasting ages of habitats. Our results showed that habitat temporal structure is a key factor shaping collembolan diversity. A reduced diversity was detected in recent habitats, especially in forests. Interactions between temporal continuity and habitat quality were also detected by taking into account soil properties: diversity increased with soil carbon content, especially in old forests. Negative effects of habitat age on diversity were stronger in isolated patches. We conclude that habitat temporal structure is a key factor shaping collembolan diversity, while direction and amplitude of its effect depend on landuse type and spatial isolation.

\section{Introduction}

Habitat fragmentation is well known to be a major threat to biodiversity in many macroorganisms (Saunders et al., 1991; Tilman, 1994; Tilman et al., 1994; Finlay et al., 1996; Stratford and Stouffer, 1999; Cushman, 2006; Mapelli and Kittlein, 2009; Krauss et al., 2010). Biodiversity is not only driven by local environmental conditions, but also by spatial processes (Hanski, 1994; Ettema and Wardle, 2002; Holyoak et al., 2005). It is now largely recognized that ecological processes shaping communities occur at least at two distinct organisation levels (Shmida and Wilson, 1985; Ricklefs, 1987; Wardle, 2006). (1) Regional processes occur since habitats within a landscape are interconnected by dispersal, which gives birth to meta-community dynamics (Gilpin and Hanski, 1991; Hubbell, 2001; Leibold et al., 2004). At regional scale, an increase in habitat spatial connectivity increases the probability of a species to reach an unoccupied habitat and thus may enhance local diversity (Bailey, 2007; Brückmann et al., 2010). (2) Local factors such as environmental conditions and competition between organisms act as filters enabling species to maintain a viable population in a patch of habitat (Decaëns et al., 2011; Petit and Fried, 2012) and thus reduce local diversity. Within this framework, patches are defined as spatial units of habitat differing from the surrounding area (Forman and Godron, 1986). Even though patches may display an internal heterogeneity at finer scale, e.g. microhabitat (Leibold et al., 2004), they contain a single type of 
habitat defined by relatively homogeneous biotic and abiotic factors such as temperature, humidity or

54 vegetation cover.

In fragmented landscapes, biodiversity can be locally reduced when patches become too small to sustain a species or when species are not mobile enough to efficiently recolonize patches where they went extinct. Characteristics of habitat patches (e.g. vegetation cover, configuration, shape and area) also have various effects on biodiversity (Forman, 1995; Tanner, 2003; Davies et al., 2005) depending on how the focal group of organisms perceives the surrounding landscape and on its ability to move from a patch to another (Kotliar and Wiens, 1990; Ettema and Wardle, 2002; Tews et al., 2004). While the effects of fragmentation are well documented for aboveground animals such as birds or amphibians (Stratford and Stouffer, 1999; Cushman, 2006) they have hardly been studied in soil organisms (Decaëns, 2010). However, soil fauna is the most species-rich component of ecosystems (André et al., 1994), known to provide many ecosystem services (Lavelle et al., 2006) that could be negatively impacted by habitat fragmentation. Soil invertebrates are known to have a low active mobility because of their small body size (Finlay et al., 1996; Hillebrand and Blenckner, 2002) and because it is more difficult to move within the soil than above it. For these reasons they should not react to habitat fragmentation in the same way as larger aboveground animals. We tackle here these general issues using Collembola as a model and focussing on the impact of habitat spatiotemporal structure on their diversity. Collembola constitute a relevant model because (1) they are very abundant in most soils and ecosystems, (2) many species can be found in a single location and (3) collembolan species are known to differ in their dispersal abilities and their level of specialisation for different habitat types (Ponge et al., 2006; da Silva et al., 2012).

Recent insights into the influence of landscape structure on collembolan diversity showed that at patch scale, collembolan (alpha) diversity in forests may respond negatively to habitat diversity at landscape scale (Ponge et al., 2003; Sousa et al., 2006). In these cases, the decrease in local or alpha diversity was attributed to habitat fragmentation occurring in diverse landscapes. Indeed, patch isolation which is most of the time increased in fragmented habitats, may reduce the chances of colonization by species, especially if these have poor dispersal ability (Hewitt and Kellman, 2002). In contrast, Querner (2013) showed that landscape heterogeneity may increase local (alpha) collembolan 
81 diversity in oilseed rape fields (i.e. in agricultural habitats). In this case, species are thought to express

preferences for different habitat types so that regional (gamma) diversity is increased by habitat heterogeneity (Vanbergen et al., 2007). Since these preferences are not strict, and species move between patches, habitat heterogeneity in the neighbouring landscape would also increase diversity at patch scale (alpha diversity). These results suggest that it is difficult to predict a priori the impact of habitat isolation on local (alpha) species diversity and that this impact depends on the ecosystem under investigation. Here, we compare the effect of patch isolation in two broad habitat types, open vs. closed vegetation, within the same landscape.

Most empirical studies on metacommunity dynamics assume that local communities have reached equilibrium at sampling time. However some authors suggested that the time elapsed, since the first species successfully colonized a patch of habitat, is essential for the understanding of observed diversity patterns (Mouquet et al., 2003). These authors assume that communities at the first stages of the assembly process are unsaturated because only a subset of the regional species pool has yet been able to colonize the patch. Besides spatial structure, patch temporal structure may thus also influence collembolan alpha diversity. Ponge et al. (2006) showed that landscape heterogeneity may come with a more dynamic patch temporal structure. They suggest that regions that include more diverse habitat types may also include more patches of habitat that have experienced a recent change in land use (e.g. patches that switched from forest to agriculture or the reverse, and thus are not continuous through time). This may have subsequently reduced collembolan diversity at patch scale (alpha diversity). In this sense, the lack of diversity observed in most heterogeneous landscape might be due to patch history, i.e. to temporal discontinuity, rather than to patch spatial structure, i.e. fragmentation.

Another source of complexity for understanding the influence of habitat structure on diversity patterns is that patch characteristics (age, spatial isolation, land use type) may influence local communities either directly or indirectly. They directly impact local communities through their effect on meta-community dynamics (Driscoll et al., 2012). Patch characteristics may also impact communities through complex links between landscape dynamics and local environmental properties (Wu and Loucks, 1995). For example, isolation and age of a patch can impact local microclimatic 
conditions (Saunders et al., 1991; Magura et al., 2003), and increased edge effects in isolated patches

can be responsible for changes in soil properties. In this case, patch spatial structure would be responsible for changes in local conditions which would consequently affect local (alpha) diversity (e.g. indirect effect). Conversely, pre-existing local conditions may impact land use changes (e.g. if the forest soil is fertile, the forest is more likely to be turned into a field). Such direct and indirect effects must be disentangled to determine the effects of landscape structure on local communities.

In the present study, we intend to disentangle the relative effects of spatial vs. temporal continuity of habitats on collembolan alpha diversity in both agricultural and forest habitats. We will assess the effect on diversity of 1) temporal continuity of habitats (temporal structure), 2) spatial isolation of habitats (spatial structure), 3) interaction of temporal and spatial habitat structures, 4) local environmental conditions (land use and soil) and whether they depend on habitat spatiotemporal structure (indirect effect), and 5) forest and agricultural habitats.

According to the rationale above (Ponge et al., 2006), we expect (H1) stable habitats (i.e. old 122 or temporally continuous patches) to support a higher alpha diversity than habitats that have been 123 disturbed in the past decades (i.e. recent or temporally discontinuous patches). Besides being 124 considered as stable habitats, forests display a wider variety of niches than agricultural land due to the 125 quality of their soils and humus: forests have a well-developed humus layer (often including 126 fragmented OF horizons and sometimes humified $\mathrm{OH}$ horizons) that is absent in open or agricultural 127 habitat (Hågvar, 1983 ; Ponge, 2000). Additionally, soil carbon content and moisture are higher in 128 forest than in agricultural habitats (Batlle-Aguilar et al., 2011), thereby favouring Collembola given 129 the well-known requirements of these animals in water and organic matter (Hopkin, 1997). We thus 130 expect $(\mathrm{H} 2)$ to find a higher diversity and a higher abundance of Collembola in forested habitats. We 131 think that vegetation structure in agricultural habitats makes dispersal easier than in forests because 132 passive dispersal vectors such as wind are more efficient in open than in closed vegetation (Morecroft et al., 1998). We thus expect (H3) that spatiotemporal continuity will have a lower effect in agricultural habitats when compared to forests. 


\section{Material and methods}

\subsection{Study site}

Sampling took place in the northern part of the Morvan Regional Natural Park (Burgundy, Center-East France). The study area is located in the northern part of the Park (523 6000 - 5252000 N, $573800-588800 \mathrm{E}$; WGS84, UTM 31N) and represents an area of $16 \times 15 \mathrm{~km}$. The climate is submontane-atlantic with continental influence (mean annual rainfall $1000 \mathrm{~mm}$ and mean temperature $9^{\circ} \mathrm{C}$ ). The bedrock is made of granite and soils are mostly acidic (Cambisols, IUSS Working Group WRB 2006). We selected this region because it displays diverse habitat spatiotemporal structures and relatively homogeneous soil conditions among all habitat of the same type. The region is rural, with intensive to extensive agriculture (55\%) and forestry (45\%). From the beginning of the twentieth century Douglas fir [Pseudotsuga menziesii Mirbel (Franco)] and Norway spruce [Picea abies (L.) Karst.] have been intensely planted for saw-wood production and coniferous stands have progressively replaced the formerly dominant deciduous stands. However, large areas of oak [Quercus petraea (Matt.) Liebl.] and beech (Fagus sylvatica L.) forest still subsist. Nowadays, agricultural areas consist of permanent pastures (40\%), hay meadows (40\%) and crops (20\%). Forested areas are comprised of planted coniferous stands (45\%) and deciduous stands (mostly Ilici-Fagenion) (55\%). In this region, the landscape has experienced a dynamic period (1962 to present) due to agricultural abandonment and European subsidies that encouraged farmers to convert meadows into plantation forests. This afforestation created many recent forest patches.

\subsection{Sampling design}

Our sampling design was comprised of 60 sites (28 forested and 32 agricultural) classified in 12 combinations of three habitat descriptors: habitat type (HT), temporal continuity (TC) and spatial isolation (SI). For each spatiotemporal combination we sampled 3 to 9 replicates (Appendix A).

\subsubsection{Habitat type}

Collembolan communities are likely to depend on the dichotomy between open and closed 160 vegetation (Ponge et al., 2003; Vanbergen et al., 2007). Hence we decided to split the landscape into 
161 two major habitat types: forest and agricultural land. Thus, sampled sites can either be meadows, pastures, crops, or Christmas tree plantations for agricultural habitats and coniferous or deciduous stands for forest habitats (Appendix A). Christmas tree plantations might at first be thought as forest habitats. However, they display many characteristics of agricultural habitats: absence of litter and developed humus profiles (due to low stature and density of Christmas trees), use of ploughing and pesticides, i.e. same characteristics as agricultural land. They are generally constituted by no more than five-year-old trees and have been shown to support collembolan communities typical of agricultural habitats (Ponge et al., 2003). It is well known that the transition from deciduous to coniferous stands implies an abrupt change in soil physicochemical properties ( $\mathrm{pH}$, humus form, etc.) (Gauquelin et al., 1996; Augusto et al., 2003). However, Ponge et al. (2003) showed that in the Morvan region, collembolan communities do not differ between coniferous and deciduous stands, contrary to often-reported detrimental effects of coniferous plantations, mostly ascribed to changes in humus form and soil acidity (Cassagne et al., 2004; Hasegawa et al., 2009). In any case, collembolan communities of both forest types differ less from each other than they differ from agricultural communities. The absence of pronounced reaction of collembolan communities to tree species composition was also observed in similar acidic soil conditions in Germany (Salamon and Alphei, 2009). This is explained by the fact that on acidic bedrocks of the studied region, similar humus forms with thick litter layers and strong soil acidity (moder) develop under both stand types (Ponge et al. 1993). It has been shown that Collembola mostly feed on microorganisms and animal faeces and rarely consume directly leaves or needles (Ponge, 1991; Caner et al., 2004). As such, they are most of all influenced by humus forms whatever the composition of forest canopies (Ponge, 1993). Additionally, coniferous tree species planted in the Morvan region (Douglas fir, silver fir and more rarely Norway spruce) have a more nutrient rich litter and do not acidify the soil to the same extent as pines (Augusto et al., 2003). This allowed us to group both forest types into a single broader category. We avoided sampling in special habitats such as humid areas or clear-cuts so as to minimize the influence of particular environmental conditions within forests and agricultural land. 
In order to assess the temporal continuity of each habitat within the focus area, we

implemented a dynamic cartography (i.e. picturing both spatial and temporal continuity) using aerial photographs. In total, about two hundred aerial photographs (IGN, France) were required from 1948 to 2008 with a photograph taken approximately every five year. We categorised each habitat into two age classes (Appendix A). Those in place at least since 1948 were classified as old. Recent forests were agricultural habitats until conversion to forest 30 to 40 years ago (in our classification, a change from deciduous to coniferous stand is not a temporal discontinuity). Recent agricultural habitats were forests until conversion to agricultural land 20 to 30 years ago. Studied local collembolan communities were thus included in habitats that were homogeneous in type and age. In the context of this study, we considered that a patch is not only a continuous block of the same habitat type but also a continuous part of the same habitat type over time, meaning that we mapped four types of patch: old forest, recent forest, old agricultural and recent agricultural.

\subsubsection{Habitat spatial isolation}

Using the previously mentioned cartography, we selected sampling points in both habitat types (agriculture and forest) and habitat temporal continuity classes (recent and old) and then categorized the landscape mosaic in a buffer zone of $300 \mathrm{~m}$ radius around sampling points (Appendix A). Two 204 parameters were considered to define habitat spatial isolation: edge contrast and dominant age of the 205 matrix. Edge contrast measures the magnitude of the difference between adjacent habitat types. It is 206 calculated as the percent edge of the habitat (containing the sampling point) shared with an opposite 207 habitat within a $300 \mathrm{~m}$ radius. Opposite habitat was forest for agricultural land and vice versa. Of 208 course, edge contrast is nil or close to nil for isolation class 0 . The matrix was defined by the 209 proportion of the dominant habitat type of a given age which occupies the matrix around the sampling 210 point.

211 Isolation class 0 was comprised of large continuous habitats, i.e. larger than the scale of 212 observation around the sampling point (the $300 \mathrm{~m}$ buffer zone). Thus sampling points of isolation class 2130 (whether in recent or old habitat) were entirely included in a matrix made of the same type of habitat $214300 \mathrm{~m}$ around it (except for one recent forest patch that shared $11 \%$ of its edge with an old agricultural 
215 patch). The matrix surrounding sampling points of isolation class 0 was mostly old (continuous or

non-isolated spatial structure).

For isolation classes 1, criteria of spatial isolation slightly differed between forest and agricultural habitats. Agricultural patches of isolation class 1 shared a single edge with an old forest. The matrix surrounding them was mostly comprised of old (and less frequently recent) forest habitats. Forest patches of isolation class 1 corresponded to a particular situation that we repeatedly found in the studied region, e.g. some remnant forest patches in place since 1948 (i.e. old) that have been reconnected by a (recent) forest patch to another old forest patch since the last 30-40 years. Old forests of isolation class 1 shared 25 to $83 \%$ of their edge with an old agricultural land and the rest with a recent forest. Recent forests of isolation class 1 were the "reconnecting patches", sharing 19 to $69 \%$ of their edge with an old agricultural land and the rest with an old forest. The matrix surrounding sampling points of isolation class 1 was comprised of old and recent habitats.

For isolation class 2, spatial isolation also slightly differed between forest and agricultural habitats. Forest patches of isolation class 2 were remnant patches, entirely surrounded by an old agricultural matrix. They have been completely isolated since they are in place. Old and recent agricultural patches of isolation class 2 shared respectively 60 to $100 \%$ and 45 to $80 \%$ of their edge with a forest. The matrix surrounding agricultural patches of isolation class 2 was mostly old. Isolation class 1 was considered to be less isolated than isolation class 2 because with the appearance of recent habitats in the surrounding matrix of isolation class 1 , some newly created habitats were of the same type as the one located at the sampling point, originating in a less isolated context.

In forests as well as in agricultural land, patches of isolation classes 1 and 2 were sampled at least $10 \mathrm{~m}$ (but no more than $50 \mathrm{~m}$ ) away from the opposite habitat type edge.

\subsection{Collection of fauna and soil data}

Sampling took place from June 27 to July 9, 2010. Each site was sampled for litter/soil mesofauna using a cylindrical soil corer $(5 \mathrm{~cm}$ diameter $\mathrm{x} 7 \mathrm{~cm}$ depth, one sample at each sampling site). We thus sampled exactly the same volume of soil at each site, meaning that values of species density, i.e. the number of species per unit area sensu Gotelli and Colwell (2001) here presented 
242 correspond to the number of species found over $0.2 \mathrm{dm}^{2}$. Litter/soil were brought back to the laboratory within a week and placed in a Berlese dry-funnel extractor for 10 days. Animals were collected and stored in 70\% ethyl alcohol until identification. Collembola were mounted, cleared in chloral-lactophenol and identified to species level under a light microscope (400x magnification), according to Hopkin (2007), Potapow (2001), Thibaud et al. (2004) and (Bretfeld, 1999). A list of species is given in Appendix B.

We also sampled soils (organo mineral horizon, between 0 and $10 \mathrm{~cm}$ ) in each site in order to characterize soil physicochemical properties at each sampling site. Three samples were taken around soil fauna samples and were pooled together. Soils were air-dried and sieved to $2 \mathrm{~mm}$ before measuring total carbon (Ctot) and total nitrogen (Ntot) contents (gas chromatography), $\mathrm{pH}\left(\mathrm{H}_{2} \mathrm{O}\right)$, bioavailable phosphorus (Olsen method) and cation exchange capacity (CEC). Additionally, the top five soil centimetres were sampled using a Burger cylinder $(0.1 \mathrm{~L}$ volume $)$ and immediately packed in waterproof bags in order to determine soil moisture and bulk density. The humus form was characterized according to Brêthes et al. (1995) and the Humus index was calculated according to Ponge et al. (2002), and was used as a proxy of litter amount and recalcitrance to decay (Ponge et al., 1997; Ponge and Chevalier, 2006).

\subsection{Statistical analyses}

The following diversity indicators were calculated for each site: species density (sensu Gotelli and Colwell, 2001), i.e. the actual number of species found in each sample, species richness (sensu Gotelli and Colwell, 2001) i.e. the local number of species estimated to be found in a smaller sample containing $25 \%$ of the mean individual density (i.e. 57 individuals), Shannon index, dominance (relative frequency of the most abundant species), and abundance (total number of individuals).

These diversity indicators were analysed using linear models (type III sums of squares used for unbalanced design and because significant interactions were expected, see Appendix B), testing for habitat type (HT), spatial isolation (SI), and temporal continuity (TC) effects as well as effects of all interactions between these factors. To fulfil linear model assumptions, dominance had to be logtransformed. In order to detect possible effects of habitat spatiotemporal structure (regional factors) on 
its soil quality that could influence diversity indicators, we tested the effect of habitat descriptors on soil physicochemical properties. Most of natural or log-transformed data fulfilled the assumptions of linear models. When this was not the case, we used generalized linear models with a Gamma link function or a Poisson link function. All possible correlations (Pearson) between diversity indicators and soil properties were calculated and tested. We also calculated and tested these correlations in both habitat types separately.

Finally, we constructed complete linear models, testing the effects of the three habitat descriptors on diversity indicators and including most important soil parameters as covariates, together with all their interactions. Since there are many combinations of habitat descriptors and many soil parameters it was not possible to include all of them and their interactions in a single model. Therefore we focussed our analysis on the two soil parameters that were the most correlated with diversity and/or that were significantly affected by habitat descriptors, i.e. Ctot and $\mathrm{pH}$. These two variables can be considered as proxies for two main physico-chemical factors which impact collembolan communities at two different scales (species or community): Ctot is a proxy for general habitat and resource availability and thus determines the total abundance; and $\mathrm{pH}$ is a proxy for local environmental filter which selects species within communities, since several collembolan species are only adapted to low or high soil acidity (Ponge, 1993; Salmon, 2004). We analysed two models testing separately for the effect of these two variables, the three habitat descriptors and all their interactions (two-, three- and four-way interactions). Simple effects of variables and interactions that were kept in each final model were selected using an automatic selection procedure based on AIC (procedure step, with backward direction, Bodzogan, 1987; Posada and Buckley, 2004). Combinations of habitat descriptors were compared using least square means and associated multiple comparisons of means (Tukey). All statistical analyses were performed using Mass, car, vegan and Lsmeans packages of R software ( $R$ Development Core Team, 2010).

Altogether, these analyses enabled us to discriminate between direct and indirect effects. The first type of models (testing the effect of the three habitat descriptors on diversity indicators) includes 295 both direct and indirect effects of spatiotemporal structure. If the second type of models (testing the 296 effect of the three habitat descriptors on soil properties) reveals significant effects, it means that 
indirect effects are likely to occur. Even if they do not, little differences in soil properties between habitat spatiotemporal structures could still slightly influence collembolan diversity. This is why we constructed a third type of models, testing for the effect of the three habitat descriptors on diversity and including an influential soil property in the same model. If simple effects of habitat descriptors are significant, it means that they have a direct effect on diversity. However, if simple effects of soil properties are significant, indirect effects are occurring. The comparison of the first and third types of models enabled us to assess whether direct or indirect effects were occurring or if both effects were present at the same time (Fig. 1).

\section{Results}

\subsection{Effects of the three habitat descriptors on collembolan diversity}

In total, 6339 individuals were identified to 70 species. We found 3639 from 57 species in forest and 2700 individuals from 39 species in agricultural habitats. In forests, 44 species were found in old sites and 42 in recent sites. In agricultural land, 36 species were found in old sites and 24 species in recent sites. Thirteen species were present in recent forests but not in old forests and 15 species were present in old forests and not in recent forest. In agricultural sites, 15 species were 312 present in old but not in recent sites and only 3 species not present in old sites were found in recent 313 sites. Rarefaction curves (Fig. 2) showed that our sampling was nearly exhaustive for both habitat 314 types whatever old or recent, and that forests (both recent and old) harbored more species in total 315 (gamma diversity) than agricultural land (old > recent). Statistical models implemented on diversity 316 indicators (Model type 1 in Fig. 1, Table 1) showed that habitat type (HT) exerted an effect on species 317 density, species richness and total abundance. Species density, species richness as well as abundance 318 of Collembola were higher in forest compared to agricultural habitats (on average respectively 11.4 319 versus 8.6 for species density and 9.1 versus 7.9 for species richness). However, no effect of HT was 320 detected either on Shannon index or on dominance. Furthermore, only Shannon index, species richness 321 and species density responded to habitat temporal continuity (TC), old habitats showing higher values 322 than recent habitats (on average 10.8 versus 9.3 for species density, 1.8 versus 1.6 for Shannon index, 323 and 9.1 versus 7.5 for species richness). Multiple comparisons among means (Tukey) showed that this 
effect was mainly due to differences between old and recent forests (on average respectively 13.1 and 9.4 for species density, 1.9 and 1.5 for Shannon index, and 10.2 versus 7.9 for species richness), whereas old and recent agricultural lands showed closer values (on average respectively 9.1 versus 7.7 for species density, 1.7 versus 1.5 for Shannon index, and 8.3 versus 7.1 for species richness) (Fig. 3). Both coniferous and deciduous forests displayed significantly lower values for species density, species richness and Shannon index in the recent age class compared to the old one (data not shown). We did not detect any effects of spatial isolation (SI) on diversity indicators, either in forest or in agricultural habitats, and no interaction between habitat descriptors (Fig. 4).

\subsection{Effects of the three habitat descriptors on soil characteristics}

Most soil properties were significantly different according to HT. Models testing the effect of HT on soil properties showed that CEC, Ctot, C:N and Humus index had significantly higher values in forest than in agricultural habitats, whereas soil density, soil moisture and $\mathrm{pH}$ showed opposite trends (Model type 2 in Fig. 1, Tables 2 and 3). On the other hand, only a few of them, i.e. pH, $\mathrm{P}$ and C:N, responded to the two other habitat descriptors (SI and TC). Soil pH, bioavailable phosphorus, and 338 carbon to nitrogen ratio $(\mathrm{C}: \mathrm{N})$ showed differences between isolation classes. Soil $\mathrm{pH}$ was higher in 339 isolation class 1 (on average 4.3) than in isolation classes 0 and 2 (on average respectively 3.7 and 340 3.8), but only in forest patches, resulting in a significant interaction between HT and SI. Bioavailable 341 phosphorus content was higher in isolation class 2 than in isolation classes 0 and 1 (on average 342 respectively 74, 55 and $44 \mathrm{mg} / \mathrm{kg}$ ). Only C:N was significantly impacted by TC and was higher in old 343 habitats than in recent ones. Moreover, for C:N, many interactions between habitat descriptors were 344 significant (Table 3). Multiple mean comparisons showed that these effects were mostly due to non345 isolated old forest habitats (isolation class 0 ) that showed significantly higher values (on average 20.6) 346 than every other forest habitats whatever their SI or TC (in old habitats: isolation 1, 15.8; isolation 2, 347 16; in recent habitats: isolation $0,14.5$; isolation $1,14.3$; isolation $2,13.8$ ). In agricultural land, no 348 effect of the spatiotemporal descriptors on C:N was detected. 


\subsection{Effects of the three habitat descriptors and soil characteristics on collembolan diversity}

When implemented on data from both forest and agricultural habitats, no correlations between Shannon index and soil properties were significant (Fig 5). On the other hand, many correlations between species density and soil properties were significant at 5\% level. Species density was positively correlated with $\mathrm{CEC}, \mathrm{Ctot}, \mathrm{C}: \mathrm{N}$ and Humus Index $(0.37 ; 0.38 ; 0.43$ and 0.44 , respectively) and negatively correlated with bulk density and $\mathrm{pH}$ (-0.3 and -0.38 , respectively) (Fig 5). Only positive correlations between species richness and Ctot, C:N, CEC and Humus index (respectively $0.30,0.27,0.28$ and 0.33 ) were observed. However, most of these correlations reflected the abovementioned differences in soil properties between forest and agricultural habitats. When implemented separately in the two HTs no correlations with species density, species richness or Shannon index were significant in agricultural habitats. In forests, only Ctot, $\mathrm{C}: \mathrm{N}(0.4$ and 0.44 , respectively) and $\mathrm{pH}$ ($0.39)$ were significantly correlated to species density and only C:N was significantly correlated to species richness (0.40), but none were correlated to the Shannon index (Fig. 5).

As C:N was highly correlated with both $\mathrm{Ctot}$ and $\mathrm{pH}(0.61, \mathrm{p}<0.0001$ and $-0.69, \mathrm{p}<0.0001$ respectively), while Ctot and $\mathrm{pH}$ were also correlated $(0.43, \mathrm{p}<0.001)$ but to a lesser extent than to $\mathrm{C}: \mathrm{N}$, we decided to include only Ctot and $\mathrm{pH}$ as covariates in two distinct global linear models testing their effect and that of habitat descriptors on species density, species richness and Shannon index and we implemented a procedure of automatic selection based on AIC. Both models (Ctot and $\mathrm{pH}$ ) did not detect any significant effect of any variable on the Shannon index. Table 4 displays the results of models analyzing the effects of habitat descriptors and either Ctot or $\mathrm{pH}$ on species density and species richness. The Ctot models showed that there was no simple effect of habitat descriptors either on species density or on species richness, whereas $\mathrm{pH}$ models showed significant effects of HT and TC on species density and of $\mathrm{TC}$ on species richness. Additionally, $\mathrm{pH}$ and Ctot models revealed the effect of several significant interactions. The $\mathrm{pH}$ model showed significant effects of the interactions between HT and TC, between HT and SI and between TC and SI on species density. The Ctot models showed the effect of interactions between HT and SI on species density, and between TC and SI on both species density and species richness. Indeed, least square means for species density comparison (Fig. 6a) obtained with the Ctot model showed no difference between both HTs in non-isolated 
habitats (isolated class 0) whereas it showed significantly higher values in forest than in agriculture in isolation classes 1 and 2. Moreover, comparisons of least square means for species density showed significantly higher values in old than in recent patches for the isolation classes 1 and 2 , while it showed no difference between age classes for the continuous habitats (Fig. 6b). Similarly, least square means for species richness comparison showed significantly higher values in old than in recent patches for the isolation class 2, while it showed no difference between age classes for habitats of isolation class 0 and 1 (Fig. 6c). Soil pH and Ctot did not have a significant effect on their own, neither on species density nor on species richness. The Ctot had significant effects in interaction with HT, and TC on species density. According to estimated model parameters, species density increased more with Ctot in old than in recent habitats. It also increased more with Ctot in forest than in agricultural land. The soil $\mathrm{pH}$ had significant effects in interaction with HT, TC and SI on species density and in interaction with TC on species richness. Species density decreased with the $\mathrm{pH}$ in forests whereas it increased with the $\mathrm{pH}$ in agricultural habitats. Species density and species richness also decreased with the $\mathrm{pH}$ in old habitats whereas it did not change according to $\mathrm{pH}$ in recent habitats.

\section{Discussion}

\subsection{Effects of habitat temporal continuity on collembolan diversity}

The total number of species (gamma diversity) was higher in old than in recent forests.

394 Species present in recent forests and not in old ones were all rare species (i.e. found in less than $10 \%$ 395 of the records), except for 3 species (Isotoma viridis, Lepidocyrtus cyaneus and Lepidocyrtus 396 lignorum). These species are known as agricultural-preferring species in the studied region (Ponge et 397 al., 2003, 2006). Furthermore, they were found exclusively in isolation classes 1 and 2 . Thus it is 398 difficult to know whether they were present as relics of the past HT (i.e. agricultural land) or if they 399 colonized forest patches from the neighboring agricultural matrix. However, the fact they were not 400 present in the equivalent isolation class of old forests suggests that they beneficiated from the presence 401 of a non-saturated community in recent forests. Indeed, the fact that all niches were not necessarily 402 occupied in recent forests was certainly in favor of the persistence of agricultural-preferring species: 403 these species might colonize spatially isolated patches but would not be able to persist in the more 
404 diverse communities present in old forests of comparable spatial isolation. In agricultural land, the

total number of species was also higher in old than in recent sites. Only three species present in recent sites were absent in old ones. Among the 15 species that were present in old but not in recent sites, only three were common species (i.e. present in more than $10 \%$ of the records) and no common species were found in recent but not in old agricultural sites. This shows that even in open habitats such as agricultural land, the total number of species was reduced in recently created habitats. It is still difficult to draw any conclusion on differences in the number of rare species, but the fact that some common species were lacking in recent sites only, allows us to conclude that this absence is due to the temporal continuity of the habitat and not to some random mechanism.

Our results show that habitat temporal discontinuity impacts negatively species density, species richness and Shannon index but not the total abundance of Collembola. For a similar number of individuals, recent habitats showed fewer species than old habitats whatever the habitat type or the spatial continuity. This suggests that resources not taken by species still lacking in recent habitats are used by larger populations of existing species. Among the variables under study, only the carbon to nitrogen ratio reacted to temporal continuity, but this was due to the particular situation of spatially continuous (non-isolated) old forests that displayed higher values than every other forest patches whatever their spatiotemporal structure. All other soil properties (humus type, a proxy of litter amount and quality, $\mathrm{pH}, \mathrm{C}, \mathrm{N}$ contents and $\mathrm{P}$ availability) were similar in old and recent habitats of the same type, suggesting that habitat temporal continuity has a direct effect on collembolan diversity that does not depend on soil properties. Within the limits of our analytical protocol (we did not study all parameters known to influence Collembola, such as for instance the composition of litter and that of soil microbial communities, nor did we study interactions between Collembola and higher trophic levels) this confirms our first hypothesis (H1) predicting a lower collembolan diversity in recently created habitats.

The direct effect of habitat temporal continuity on collembolan diversity is also supported by the fact that both species density and species richness were impacted by temporal continuity in the $\mathrm{pH}$ model. This means that habitat temporal discontinuity impacts diversity not only by decreasing the size of the local pool of species (species density) but also by decreasing the number of species that 
432 would be present if local soil conditions were strictly similar among all spatiotemporal situations

(species richness). This is supported by the fact that the impact of temporal continuity on Shannon index must be considered as a direct effect because this index did not show any significant correlation with soil physicochemical properties.

However, the temporal discontinuity of habitat could also be viewed as an index of 437 disturbance. According to the intermediate disturbance hypothesis we could expect recent habitats to 438 host low collembolan diversity, habitats of intermediate age to host a higher biodiversity, and 439 biodiversity to decrease in older habitats because of exclusive competition (Connell, 1978; Molino and 440 Sabatier, 2001; but see Fox, 2013). Our results did not support this general scheme. This might be due 441 to the fact that our study focuses on the landscape scale, so that studied habitat were not homogeneous 442 and host a high diversity of local niches at scales ranging from units to tens square meters (Ponge and 443 Salmon, 2013). Nevertheless, we cannot exclude that habitats older than the ones we studied, might 444 display a decrease in collembolan biodiversity, thus supporting the intermediate disturbance 445 hypothesis. We did not expect old most isolated habitats to display the lowest alpha diversity predicted 446 by metacommunity theories (Tilman, 1982; Hubbell, 2001) because the oldest habitats we studied 447 were certainly not old enough to support such patterns. Additionally, within-patch heterogeneity is 448 most likely to prevent collembolan alpha diversity from decreasing to such low levels.

Most empirical studies testing the effect of landscape structure on diversity patterns do not take habitat temporal structure into account (Mouquet et al., 2003). We do not have knowledge of any other study on Collembola that is strictly comparable to ours although collembolan species have been 452 shown to be affected by habitat successional stage (Setälä et al., 1995; Loranger et al., 2001; Scheu et 453 al., 2003; Chauvat et al., 2007; Salamon et al., 2008; Chauvat et al., 2011). While in these studies the 454 observed effects were due both to change in habitat type (succession) and to habitat age (time since the 455 habitat is in place) our results allow us to focus on the effect of habitat age within the same habitat 456 type. Temporally discontinuous (recent) habitats displayed lower diversities due to the poor 457 colonization/dispersal abilities of Collembola: some species were absent from recent habitats not 458 because the habitat was not suitable for them but because they did not have enough time to colonize it. 459 Higher values of the Shannon index in old than in recent habitats support this hypothesis: communities 
460 in recent habitats are dominated by fewer species. Coined as colonization credit, this process has been

suggested to occur in plant communities (Cristofoli et al., 2010), but has so far been documented by only a few empirical studies on plants (Gijbels et al., 2012) and butterflies (Cristofoli and Mahy, 2010). All these studies showed that specialist species are more affected than generalist species.

\subsection{Effect of habitat spatial isolation on collembolan diversity}

In this study, we tested two main possible effects of spatial isolation on diversity: the indirect effect of isolation through its effect on environmental conditions and its direct effect through its influence on species likelihood to colonize and persist in a patch. We detected no consistent effect, either direct or indirect, of habitat spatial structure on collembolan diversity, among the two habitat types and the two age classes here compared.

Habitat fragmentation is thought to decrease the local diversity of macroorganisms because isolated patches (i) are too small to fulfill ecological and demographic requirements of populations (Allouche et al., 2012), and (ii) are more difficult to colonize (Wamser et al., 2012). We did not find such effect in Collembola. This is probably because our habitat patches were always large enough to fulfill ecological and demographic requirements of all potentially present collembolan species due to the small size of these organisms. Schneider et al. (2007) showed indeed that collembolan populations in patches as small as $50 \mathrm{~cm}^{2}$ did not change both in diversity and density within 16 months of isolation. Given that our smallest patch was much larger than this restricted surface, this may explain why spatial discontinuity did not affect collembolan populations in our study. Thus, even if the colonization of isolated patches might be a problem for them (see section 4.3), fragmentation has 480 probably not led to local extinctions, so that colonization is not necessary to maintain diversity. Of 481 course, the connectivity and the size of micro-habitats inside the patches may influence collembolan 482 diversity at micro-site scale (Hertzberg, 1997; Åstrom and Bengtsson, 2011) but our sampling design 483 does not allow testing this hypothesis. 


\subsection{Interacting effects of habitat temporal and spatial structure on diversity}

Our results showed that spatial and temporal structures of habitats had an interactive effect on local diversity patterns. In the studied region, we showed that species diversity increased with spatial isolation in old habitats whereas it decreased with spatial isolation in recent habitats. This resulted in differences of diversity in isolated habitats while recent and old continuous habitats showed similar values. This suggests that when in place for a long time, isolated habitats supported more colonization events than spatially continuous (i.e. non-isolated) habitats, without concomitant extinction events. This can be due to species from the opposite habitat type being present locally, if they do not have strict habitat preferences, because of increased edge effects in isolated patches (Slawski and Slawska, 2000; Östman et al., 2009). This also means that the negative effect of spatial isolation on collembolan diversity can only be unravelled if we take the habitat temporal structure into account. Our results suggests that Collembola species need time to colonize recently created habitat that are isolated from other habitats of the same type. This effect should be especially strong for specialist species that do not survive in a matrix of the opposite habitat type. To our knowledge, it is the first time that such interacting effects are empirically unravelled.

The interaction between habitat spatial and temporal continuity was not strictly similar for species density and species richness. Indeed, species density was lower in recent than in old habitat of isolation classes 1 and 2, whereas species richness was lower in recent than in old habitat of isolation 2 only. By definition, species density is affected by the number of individuals present in a sample, while species richness is not. Species density should thus be sensitive to both local factors and landscape characteristics (regional factors). Local factors determine locally the carrying capacity of the environment while the number of species that can reach a local patch should be mostly determined by landscape characteristics. This difference in sensitivity between both diversity indicators reveals that old habitat of isolation class 1 should benefit from the contribution of many poorly abundant species (not taken into account in the calculation of species richness) in addition to a few abundant species. This results in similar values of species richness in old and recent habitats of isolation class 1, but still different values for species density. In the other hand, old habitats of isolation class 2 benefit from an 
511 increase in the number of species that are also more evenly distributed, which results in an increase in

both species richness and species density compared to recent habitat of the same isolation class.

These results support the novel idea that habitat fragmentation constrains diversity not only through spatial but also through temporal continuity: there is a strong positive impact of temporal continuity on the total number of species, in addition to the distribution of individual numbers within each species. Thus, in the case of soil organisms, which probably disperse slowly at landscape scale, regional processes shaping communities must be slow. That is why habitat age has to be taken into account to better predict soil biodiversity in the context of habitat fragmentation.

\subsection{Effect of soil properties in interaction with habitat spatiotemporal structure on diversity}

Few soil characteristics responded to the spatial and /or temporal structure of habitats, suggesting that indirect effect on diversity should be weak. Additionally, our results showed that both species density and species richness were submitted to direct effects of habitat descriptors and their interactions, whereas no indirect effects were detected since neither the Ctot nor the soil $\mathrm{pH}$ had simple effect on diversity. However, the two parameters that were most correlated with species density (soil $\mathrm{pH}$ and total carbon Ctot) interacted with habitat descriptors to affect diversity. Collembolan diversity was more influenced by Ctot and soil $\mathrm{pH}$ in old than in recent patches. This result corroborates the study of Dzwonko (2001), who showed that plant species indicator values for several environmental factors (Ellenberg indicators) were more reliable in old than in recent forests. Species can be good indicators of environmental conditions only if communities have had enough time to reach equilibrium. Before equilibrium, a bias can occur because some indicator species are lacking due to dispersal limitation (Seabloom and van der Valk, 2003) or because some species reflecting previous habitat type still persist (French et al., 2008).

The introduction of Ctot in the model suppressed the significant effect of temporal continuity on species density. Likewise, the introduction of the $\mathrm{pH}$ in the model suppressed the significant effect of habitat type on species richness. This means that a part of the variability explained by habitat descriptors is in fact due to a difference in soil properties. Ctot was lower (although not significantly) in recent than in old habitats, especially in forest and soil $\mathrm{pH}$ was significantly lower in forest than in 
538 agricultural land. Since the carbon content and the soil $\mathrm{pH}$ may influence collembolan diversity

(Chagnon et al., 2000), we cannot totally reject that a part of the observed difference in diversity according to habitat descriptors is due to slightly different environmental conditions. This shows that discriminating between direct and indirect effects is not straightforward, confirming that when studying the impact of landscape structure on soil animals, soil properties should be taken into account.

We also showed that effects of habitat descriptors on species density and species richness were not strictly similar when taking into account soil properties. Fewer effects were detected on species richness than on species density, but all factors impacting species richness also impacted species density. This suggests that some factors impacting species density also impact species relative abundances in a subtle way and that removing this effect on abundances through the use of species richness suppresses the effects detected on diversity. This confirms that using an abundance-free index of biodiversity using rarefaction curves allows a better analysis of the impact of local and regional factors on local pools of species (Gotelli and Colwell, 2001).

\subsection{Differences in diversity patterns between habitat types}

We defined habitat types as two very broad categories: agriculture or forest without taking the precise habitat type (e.g. coniferous and deciduous forests) into account. Nevertheless, we were able to reveal some significant effects of landscape characteristics on diversity and differences in patterns between the two habitat types. This confirms that for Collembola, the land use is a fundamental factor that determines which species can persist locally (Ponge, 1993; Hopkin, 1997; Birkhofer et al., 2012). 558 As hypothesized (H2), local diversity in terms of species density and species richness were higher in 559 forest than in agricultural habitats. This is likely to be due to differences in soil properties between 560 these two contrasted habitat types. (1) Forests display well developed humus profiles and a higher soil 561 carbon content, which provide resources for many collembolan species (Chagnon et al., 2000). The 562 absence of tree cover and the exportation of organic matter and associated nutrients in agricultural 563 land result in a reduced soil organic layer and soil moisture (Batlle-Aguilar et al., 2011) which will 564 consequently negatively affect diversity and abundance of soil biota. Additionally, higher soil density 
in agricultural habitats may also reduce collembolan abundance because it provides little pore space for soil-dwelling populations (Vreeken-Buijs et al., 1998). It is not excluded that other biotic factors such as predation contributed to drive observed diversity patterns. However, our field study did not allow assessing the impact of such factor. Surprisingly, in our study, habitat type had no effect on the Shannon index. Based on the mathematical expression of Shannon's diversity, which associates a probability of occurrence to each species, this discrepancy suggests that even though the number of species differed, less frequent species were most affected by change in habitat type (Gorelick, 2006). The effect of temporal discontinuity was stronger in forest than in agricultural land. This finding supports our third hypothesis (H3) that predicted a stronger effect of habitat spatiotemporal structure on collembolan diversity in forest than in agricultural habitats. This could arise because open habitats lead to more efficient dispersal either through passive or active mechanisms. First, if Collembola have a preponderant passive dispersal and are directly or indirectly transported by wind, as suggested for some species by Dunger et al. (2002) and Coulson and Midgley (2012), their 578 colonization rate might be higher in agricultural habitats since air flow is stronger in the absence of 579 tree cover (Wright et al., 2010). This result is in accordance with other findings on Collembola in 580 deglaciated land (Ingimarsdottir et al., 2012). Indeed these authors showed that in such extremely open 581 habitat (i.e. with reduced to nil vegetation cover) collembolan dispersal rate was potentially high. 582 Another explanation could be that collembolan communities in agricultural land are comprised of 583 more epigeic species than in forests (Sousa et al., 2004), with morphological traits (e.g. long legs, long 584 furcula) supposed to allow higher mobility in open habitats (Salmon and Ponge, 2012). This result 585 suggests that dispersal rates and modes are habitat-dependent as shown in other microarthropod 586 groups (Lindo and Winchester, 2009).

Our results also showed a significant interaction between spatial isolation and habitat type. 588 With spatial isolation, species density increased in forest but decreased in agricultural habitats. This 589 could be due to better mobility and less strict habitat preferences of species found in agricultural 590 communities (Lauga-Reyrel and Deconchat, 1999; Ponge et al., 2006), likely to be present in remnant 591 forest patches. In contrast, many species from the forest communities show strict habitat preferences 592 and a reduced mobility (Auclerc et al., 2009) and are thus less prone to colonize remnant agricultural 
patches. Our results also suggest that the forest matrix surrounding agricultural patches is more difficult to cross for species than the agricultural matrix surrounding forests. Since passive dispersal by wind is likely to be more efficient in agricultural lands than in forests, this suggests that largely overlooked passive dispersal mechanisms might be influential for collembolan communities and metacommunity dynamics.

\section{Conclusion}

Our study contributes to some extent to disentangle complex effects of habitat characteristics (i.e. spatiotemporal structure and local physicochemical conditions) on collembolan diversity. Most importantly, we showed that habitat temporal continuity is a key factor shaping collembolan diversity and that we must take it into account if we want to understand the effects of habitat spatial structure. We also showed that using both species richness and species density as indicators of biodiversity allows refining the analysis of the factors influencing collembolan diversity at different scales. Unfortunately, it is rather impossible to experiment at landscape scale, and the limits of our study must be clearly defined. We controlled only partly the factors thought to influence collembolan diversity: climate and litter quality could not be controlled, as they can be in experimental conditions (Åström and Bengtsson, 2011; Bokhorst et al., 2012). Similarly, the different levels of isolation and age were broadly defined and not totally equivalent in forest and agricultural habitats. However, we were able to detect several effects of our treatments (habitat type, isolation and patch age), using landscape past dynamics as a surrogate for a strict experimental approach. Some theoretical models predicted such patterns (Green and Sadedin, 2005; Gardner and Engelhardt, 2008), but empirical corroborating 613 studies are still scarce (Lemaître et al., 2012). Nevertheless, we showed that habitat fragmentation 614 constrains diversity not only in space but also in time. The temporal continuity of habitats is one of the 615 factors that have a positive effect on diversity. Soil organisms disperse slowly compared to above616 ground biota and it hence takes longer for a recent habitat to build up soil diversity especially if the 617 patch is very isolated.

Assembly theory is now well recognized in community ecology but still little applied in soil ecology. This metacommunity framework predicts four models that could explain species distribution 
620 at local scale (Leibold et al, 2004). These models essentially differ in the importance given to dispersal

process in explaining metacommunity dynamics. Two of them, 'species sorting' (environmental constraints control species distribution) and 'mass effect' (dispersal redistributes species among habitats independently of environmental constraints) were found relevant to collembolan communities by da Silva et al. (2012) and Ingimarsdottir et al. (2012). This study also supports the idea that dispersal plays an important role in structuring collembolan metacommunities and that the magnitude and direction of its effect depend on the type of habitat considered.

\section{Acknowledgments}

This study was sponsored by the R2DS program of the Conseil Régional d'Ile-de-France. We would like to thank the public and private owners of the sampling sites for allowing the study to be carried out on their land. We would like to tank the IRD (Centre Fance Nord) and the MNHN (Brunoy) for the access to their facilities and material; the Laboratoire des Moyens Analytiques (IRD, Dakar) for performing the soil analysis; the IGN (France) for providing aerial photographs; Joshua Lobe for correction of the English language; Thibaud Decaëns for useful advices about the use of species rarefaction curves; anonymous reviewers for their useful comments which have helped us to increase the quality of the manuscript. 


\section{References}

Allouche, O., Kalyuzhny, M., Moreno-Rueda, G., Pizarro, M., Kadmon, R., 2012. Area-heterogeneity tradeoff and the diversity of ecological communities. Proceedings of the National Academy of Sciences of the United States of America 109, 17495-17500.

André, H.M., Noti, M.I., Lebrun, P., 1994. The soil fauna: the other last biotic frontier. Biodiversity and Conservation 3, 45-56.

Åström, J., Bengtsson, J., 2011. Patch size matters more than dispersal distance in a mainland-island metacommunity. Oecologia 167, 747-757.

Auclerc, A., Ponge, J.F., Barot, S., Dubs, F., 2009. Experimental assessment of habitat preference and dispersal ability of soil springtails. Soil Biology and Biochemistry 41, 1596-1604.

Augusto, L., Dupouey, J.L., Ranger, J., 2003. Effects of tree species on understory vegetation and environmental conditions in temperate forests. Annals of Forest Science 60, 823-831.

Bailey, S., 2007. Increasing connectivity in fragmented landscapes: an investigation of evidence for biodiversity gain in woodlands. Forest Ecology and Management 238, 7-23.

Batlle-Aguilar, J., Brovelli, A., Porporato, A., Barry, D.A., 2011. Modelling soil carbon and nitrogen cycles during land use change. A review. Agronomy for Sustainable Development 31, 251274.

Birkhofer, K., Schöning, I., Alt, F., Herold, N., Klarner, B., Maraun, M., Marhan, S., Oelmann, Y., Wubet, T., Yurkov, A., Begerow, D., Berner, D., Buscot, F., Daniel, R., Diekötter, T., Ehnes, R.B., Erdmann, G., Fischer, C., Foesel, B., Groh, J., Gutknecht, J., Kandeler, E., Lang, C., Lohaus, G., Meyer, A., Nacke, H., Näther, A., Overmann, J., Polle, A., Pollierer, M.M., Scheu, S., Schloter, M., Schulze, E.D., Schulze, W., Weinert, J., Weisser, W.W., Wolters, V., 
Bodzogan, H., 1987. Model selection and Akaike's Information Criterion (AIC)! The general theory and its analytical extensions. Psychometrika, 52, 345-370.

Bokhorst, S., Phoenix, G.K., Bjerke, J.W., Callaghan, T.V., Huyer-Brugman, F., Berg, M.P., 2012. Extreme winter warming events more negatively impact small rather than large soil fauna: shift in community composition explained by traits not taxa. Global Change Biology 18 , $1152-1162$.

Bretfeld, G., 1999. Synopses on Palaearctic Collembola, II Symphypleona. Abhandlungen und Berichte des Naturkundemuseums, Görlitz.

Brêthes, A., Brun, J.J., Jabiol, B., Ponge, J.F., Toutain, F., 1995. Classification of forest humus forms: a french proposal. Annales des Sciences Forestières 52, 535-546.

Brückmann, S.V., Krauss, J., Steffan-Dewenter, I., 2010. Butterfly and plant specialists suffer from reduced connectivity in fragmented landscapes. Journal of Applied Ecology 47, 799-809.

Caner, L., Zeller, B., Dambrine, E., Ponge, J.F., Chauvat, M., Llanque, C., 2004. Origin of the nitrogen assimilated by soil fauna living in decomposing beech litter. Soil Biology and Biochemistry 36, 1861-1872.

Cassagne, N., Bal-Serin, M.C., Gers, C., Gauquelin, T., 2004. Changes in humus properties and collembolan communities following the replanting of beech forests with spruce. Pedobiologia $48,267-276$.

Chagnon, M., Paré, D., Hébert, C., 2000. Relationships between soil chemistry, microbial biomass and the collembolan fauna of southern Quebec sugar maple stands. Écoscience 7, 307-316. 
Chauvat, M., Titsch, D., Zaytsev, A.S., Wolters, V., 2011. Changes in soil faunal assemblages during conversion from pure to mixed forest stands. Forest Ecology and Management 262, 317-324.

Chauvat, M., Wolters, V., Dauber, J., 2007. Response of collembolan communities to land-use change and grassland succession. Ecography 30, 183-192.

Connell, J.H. 1978. Diversity in tropical rain forests and coral reefs. Science 199, 1302-1310.

Coulson, S.J., Midgley, N.G., 2012. The role of glacier mice in the invertebrate colonisation of glacial surfaces: the moss balls of the Falljokull, Iceland. Polar Biology 35, 1651-1658.

Cristofoli, S., Mahy, G., 2010. Colonisation credit in recent wet heathland butterfly communities. Insect Conservation and Diversity 3, 83-91.

Cristofoli, S., Piqueray, J., Dufrêne, M., Bizoux, J.P., Mahy, G., 2010. Colonization Credit in Restored Wet Heathlands. Restoration Ecology 18, 645-655.

Cushman, S.A., 2006. Effects of habitat loss and fragmentation on amphibians: a review and prospectus. Biological Conservation 128, 231-240.

da Silva, P.M., Berg, M.P., Serrano, A.R.M., Dubs, F., Sousa, J.P., 2012. Environmental factors at different spatial scales governing soil fauna community patterns in fragmented forests. Landscape Ecology 27, 1337-1349.

Davies, K.F., Melbourne, B.A., Margules, C.R., Lawrence, J.F., 2005. Metacommunity structure influences the stability of local beetle communities. In: Metacommunities: Spatial Dynamics and Ecological Communities, eds. Holyoak, M., Leibold, M.A., Holt, R.D. University of Chicago Press, Chicago, pp. 170-188.

Decaëns, T., 2010. Macroecological patterns in soil communities. Global Ecology and Biogeography 19, 287-302. 
Decaëns, T., Margerie, P., Renault, J., Bureau, F., Aubert, M., Hedde, M., 2011. Niche overlap and species assemblage dynamics in an ageing pasture gradient in north-western France. Acta Oecologica 37, 212-219.

Driscoll, D.A., Whitehead, C.A., Lazzari, J., 2012. Spatial dynamics of the knob-tailed gecko Nephrurus stellatus in a fragmented agricultural landscape. Landscape Ecology 27, 829-841.

Dzwonko, Z., 2001. Assessment of light and soil conditions in ancient and recent woodlands by Ellenberg indicator values. Journal of Applied Ecology 38, 942-951.

Dunger, W., Schulz, H.J., Zimdars, B., 2002. Colonization behaviour of Collembola under different conditions of dispersal. Pedobiologia 46, 316-327.

712 Ettema, C.H., Wardle, D.A., 2002. Spatial soil ecology. Trends in Ecology and Evolution 17, 177-183.

713 Finlay, B.J., Esteban, G.F., Fenchel, T., 1996. Global diversity and body size. Nature 383, 132-133.

714 Forman, R., 1995. Land Mosaics: The Ecology of Landscapes and Regions. Cambridge University 715 Press, Cambridge.

716 Forman, R., Godron, M., 1986. Landscape Ecology. Wiley, New York.

717 Fox, J.W., 2013. The intermediate disturbance hypothesis should be abandoned. Trends in Ecology and Evolution 28, 86-92

French, L.J., Smith, G.F., Kelly, D.L., Mitchell, F.J.G., O'Donoghue, S., Iremonger, S.E., McKee, A.M., 2008. Ground flora communities in temperate oceanic plantation forests and the influence of silvicultural, geographic and edaphic factors. Forest Ecology and Management 255, 476494.

Gardner, R.H., Engelhardt, K.A.M., 2008. Spatial processes that maintain biodiversity in plant communities. Perspectives in Plant Ecology Evolution and Systematics 9, 211-228. 
Gauquelin, T., Gers, C., Deharveng, L., 1996. Physico-chemical heterogeneity of superficial soil layers in conifer plantations versus original broad leaf forests in Ariege (Pyrenees, France). Communications in Soil Science and Plant Analysis 27, 2361-2380.

Gijbels, P., Adriaens, D., Honnay, O., 2012. An orchid colonization credit in restored calcareous grasslands. Écoscience 19, 21-28.

Gilpin, M.E., Hanski, I.A., 1991. Metapopulation dynamics: Empirical and Theoretical Investigations. Academic Press, London.

Gorelick, R., 2006. Combining richness and abundance into a single diversity index using matrix analogues of Shannon's and Simpson's indices. Ecography 29, 525-530.

Gotelli, N.J., Colwell, R.K., 2001. Quantifying biodiversity: procedures and pitfalls in the measurement and comparison of species richness. Ecology Letters 4, 379-391

Green, D.G., Sadedin, S., 2005. Interactions matter: complexity in landscapes and ecosystems. Ecological Complexity 2, 117-130.

Hågvar, S., 1983. Collembola in Norwegian coniferous forest soils. II. Vertical distribution. Pedobiologia 25, 383-401.

Hanski, I., 1994. Patch-occupancy dynamics in fragmented landscapes. Trends in Ecology and Evolution 9, 131-135.

742 Hasegawa, M., Fukuyama, K., Makino, S., Okochi, I., Tanaka, H., Okabe, K., Goto, H., Mizoguchi, T., Sakata, T., 2009. Collembolan community in broad-leaved forests and in conifer stands of Cryptomeria japonica in Central Japan. Pesquisa Agropecuária Brasileira 44, 881-890.

Hertzberg, K., 1997. Migration of Collembola in a patchy environment. Pedobiologia 41, 494-505.

Hewitt, N., Kellman, M., 2002. Tree seed dispersal among forest fragments. II. Dispersal abilities and biogeographical controls. Journal of Biogeography 29, 351-363. 
Hillebrand, H, Blenckner, T., 2002. Regional and local impact on species diversity - from pattern to processes. Oecologia 132, 479-491.

Holyoak, M., Leibold, M.A., Holt, R.D., 2005. Metacommunities: Spatial Dynamics and Ecological Communities. University of Chicago Press Chicago.

752 Hopkin, S.P., 1997. Biology of the Springtails (Insecta: Collembola). Oxford University Press, Oxford.

Hopkin, S.P., 2007. A Key to Collembola (Springtails) of Britain and Ireland. Field Studies Council, Shrewsbury.

Hubbell, S.P., 2001. The Unified Neutral Theory of Biodiversity and Biogeography. Princeton University Press, Princeton.

Ingimarsdottir, M., Caruso, T., Ripa, J., Magnusdottir, O.B., Migliorini, M., Hedlund, K., 2012. Primary assembly of soil communities: disentangling the effect of dispersal and local environment. Oecologia 170, 745-754.

Kotliar, N.B., Wiens, J.A., 1990. Multiple scales of patchiness and patch structure: a hierarchical framework for the study of heterogeneity. Oikos 59, 253-260.

Krauss, J., Bommarco, R., Guardiola, M., Heikkinen, R.K., Helm, A., Kuussaari, M., Lindborg, R., Öckinger, E., Partel, M., Pino, J., Poyry, J., Raatikainen, K.M., Sang, A., Stefanescu, C., Teder, T., Zobel, M., Steffan-Dewenter, I., 2010. Habitat fragmentation causes immediate and time-delayed biodiversity loss at different trophic levels. Ecology Letters 13, 597-605.

Lauga-Reyrel, F., Deconchat, M., 1999. Diversity within the Collembola community in fragmented coppice forests in south-western France. European Journal of Soil Biology 35, 177-187. 
Lavelle, P., Decaëns, T., Aubert, M., Barot, S., Blouin, M., Bureau, F., Margerie, P., Mora, P., Rossi, J.P., 2006. Soil invertebrates and ecosystem services. European Journal of Soil Biology 42, S3-S15.

Leibold, M.A., Holyoak, M., Mouquet, N., Amarasekare, P., Chase, J.M., Hoopes, M.F., Holt, R.D., Shurin, J.B., Law, R., Tilman, D., Loreau, M., Gonzalez, A., 2004. The metacommunity concept: a framework for multi-scale community ecology. Ecology Letters 7, 601-613.

Lemaitre, J., Darveau, M., Zhao, Q., Fortin, D., 2012. Multiscale assessment of the influence of habitat structure and composition on bird assemblages in boreal forest. Biodiversity and Conservation $21,3355-3368$

Lindo, Z., Winchester, N.N., 2009. Spatial and environmental factors contributing to patterns in arboreal and terrestrial oribatid mite diversity across spatial scales. Oecologia 160, 817-825.

Loranger, G., Bandyopadhyaya, I., Razaka, B., Ponge, J.F., 2001. Does soil acidity explain altitudinal sequences in collembolan communities? Soil Biology and Biochemistry 33, 381-393.

Magura, T., Tothmeresz, B., Elek, Z., 2003. Diversity and composition of carabids during a forestry cycle. Biodiversity and Conservation 12, 73-85.

Mapelli, F.J., Kittlein, M.J., 2009. Influence of patch and landscape characteristics on the distribution of the subterranean rodent Ctenomys porteousi. Landscape Ecology 24, 723-733.

Molino, J.F., Sabatier, D., 2001. Tree diversity in tropical rain forests: a validation of the intermediate disturbance hypothesis. Science 294, 1702-1704.

Morecroft, M.D., Taylor, M.E., Oliver, H.R., 1998. Air and soil microclimates of deciduous woodland compared to an open site. Agricultural and Forest Meteorology 90, 141-156.

Mouquet, N., Munguia, P., Kneitel, J.M., Miller, T.E., 2003. Community assembly time and the relationship between local and regional species richness. Oikos 103, 618-626. 
Östman, Ö., Mellbrand, K., Hamback, P.A., 2009. Edge or dispersal effects - Their relative importance on arthropod densities on small islands. Basic and Applied Ecology 10, 475-484.

Petit, S., Fried, G., 2012. Patterns of weed co-occurence at the field and landscape level. Journal of Vegetation Science 23, 1137-1147.

Ponge, J.F., 1991. Food resources and diets of soil animals in a small area of Scots pine litter. Geoderma 49, 33-62.

Ponge, J.F., 1993. Biocenoses of Collembola in atlantic temperate grass-woodland ecosystems. Pedobiologia 37, 223-244.

Ponge, J.F., 2000. Vertical dsitribution of Collembola (Hexapoda) and their food resources in organic horizons of beech forests. Biology and Fertility of Soils 32, 508-522.

Ponge, J.F., Arpin, P., Sondag, F., Delecour, F., 1997. Soil fauna and site assessment in beech stands of the Belgian Ardennes. Canadian Journal of Forest Research 27, 2053-2064.

Ponge, J.F., Chevalier, R., 2006. Humus Index as an indicator of forest stand and soil properties. Forest Ecology and Management 233, 165-175.

Ponge, J.F., Chevalier, R., Loussot, P., 2002. Humus index: an integrated tool for the assessment of forest floor and topsoil properties. Soil Science Society of America Journal 66, 1996-2001.

Ponge, J.F., Dubs, F., Gillet, S., Sousa, J.P., Lavelle, P., 2006. Decreased biodiversity in soil springtail communities: the importance of dispersal and landuse history in heterogeneous landscapes. Soil Biology and Biochemistry 38, 1158-1161.

Ponge, J.F., Gillet, S., Dubs, F., Fedoroff, E., Haese, L., Sousa, J.P., Lavelle, P., 2003. Collembolan communities as bioindicators of land use intensification. Soil Biology and Biochemistry 35, 813-826. 
814 Ponge, J.F., Salmon, S., 2013. Spatial and taxonomics correlates of species and species trait 835 assemblages in soil invertebrate communities. Pedobiologia 56, 129-136.

Posada, D., Buckley, T.R., 2004. Model selection and model averaging in phylogenetics: advantages of Akaike Information Criterion and Bayesian approaches over likelihood ratio tests. Systematic Biology 53, 793-808.

Potapov, M., 2001. Synopses of Palearctic Collembola. III. Isotomidae. Abhandlungen und Berichte des Naturkundemuseums, Görlitz.

Querner, P., Bruckner, A., Drapela, T., Moser, D., Zaller, J.G., Frank, T., 2013. Landscape and site effects on Collembola diversity and abundance in winter oilseed rape fields in eastern Austria. Agriculture, Ecosystems and Environment 164, 145-154.

R Development Core Team, 2010. R: a Language and Environment for Statistical Computing. R Foundation for Statistical Computing, Vienna.

Ricklefs, R.E., 1987. Community diversity: relative roles of local and regional processes. Science 235, $167-171$

Salamon, J.A. and Alphei, J., 2009. The Collembola community of a Central Euroepean forest: influence of tree species composition. European Journal of Soil Biology 45, 199-206

Salamon, J.A., Scheu, S., Schaefer, M., 2008. The Collembola community of pure and mixed stands of beech (Fagus sylvatica) and spruce (Picea abies) of different age. Pedobiologia 51, 385-396.

832 Salmon, S., 2004. The impact of earthworms on the abundance of Collembola: improvement of food resources or of habitat? Biology and Fertility of Soils 40, 323-333.

834 Salmon, S. and Ponge, J.F., 2012. Species traits and habitats in springtail communities: a regional scale study. Pedobiologia 55, 295-301. 
Saunders, D.A., Hobbs, R.J., Margules, C.R., 1991. Biological consequences of ecosystem fragmentation: a review. Conservation Biology 5, 18-32.

Scheu, S., Albers, D., Alphei, J., Buryn, R., Klages, U., Migge, S., Platner, C., Salamon, J.A., 2003. The soil fauna community in pure and mixed stands of beech and spruce of different age: trophic structure and structuring forces. Oikos 101, 225-238.

Schneider, K., Scheu, S., Maraun, M., 2007. Microarthropod density and diversity repond little to spatial isolation. Basic and Applied Ecology 8, 26-35.

Seabloom, E.W., van der Valk, A.G., 2003. Plant diversity, composition, and invasion of restored and natural prairie pothole wetlands: implications for restoration. Wetlands 23, 1-12.

Setälä, H., Marshall, V.G., Trofymow, J.A., 1995. Influence of micro-habitat and macro-habitat factors on collembolan communities in Douglas-fir Stumps during forest succession. Applied Soil Ecology 2, 227-242.

Shmida, A., Wilson, M.V., 1985. Biological determinants of species diversity. Journal of Biogeography 12, 1-20.

Sławski, M., Sławska, M., 2000. The forest edge as a border between forest and meadow. Vegetation and Collembola communities. Pedobiologia 44, 442-450.

Sousa, J.P., Bolger, T., da Gama, M.M., Lukkari, T., Ponge, J.F., Simon, C., Traser, G., Vanbergen, A.J., Brennan, A., Dubs, F., Ivitis, E., Keating, A., Stofer, S., Watt, A.D., 2006. Changes in Collembola richness and diversity along a gradient of land-use intensity: a pan European study. Pedobiologia 50, 147-156.

Sousa, J.P., da Gama, M.M., Pinto, P., Keating, A., Calhoa, F., Lemos, M., Castro, C., Luz, T., Leitao, P., Dias, S., 2004. Effects of land-use on Collembola diversity patterns in a Mediterranean landscape. Pedobiologia 48, 609-622. 
859 Stratford, J.A., Stouffer, P.C., 1999. Local extinctions of terrestrial insectivorous birds in a fragmented landscape near Manaus, Brazil. Conservation Biology 13, 1416-1423.

Tanner, J.E., 2003. Patch shape and orientation influences on seagrass epifauna are mediated by dispersal abilities. Oikos 100, 517-524.

863 Tews, J., Brose, U., Grimm, V., Tielborger, K., Wichmann, M.C., Schwager, M., Jeltsch, F., 2004.

864 Animal species diversity driven by habitat heterogeneity/diversity: the importance of keystone 865 structures. Journal of Biogeography 31, 79-92.

866 Thibauld, J.M., Schultz, H.J., da Gama, M.M., 2004. Synopses on Palearctic Collembola. IV.

Tilman, D., 1982. Resource Competition and Community Structure. Princeton University Press, Princeton.

Tilman, D., 1994. Competition and Biodiversity in spatially structured habitats. Ecology 75, 2-16.

Tilman, D., May, R.M., Lehman, C.L., Nowak, M.A., 1994. Habitat destruction and the extinction debt. Nature 371, 65-66.

Vanbergen, A.J., Watt, A.D., Mitchell, R., Truscott, A.-M., Palmer, S.C.F., Ivits, E., Eggleton, P., Jones, T.H., Sousa, J.P., 2007. Scale-specific correlations between habitat heterogeneity and soil fauna diversity along a landscape structure gradient. Oecologia 153, 713-725.

Vreeken-Buijs, M.J., Hassink, J., Brussaard, L., 1998. Relationships of soil microarthropod biomass with organic matter and pore size distribution in soils under different land use. Soil Biology and Biochemistry 30, 97-106.

Wamser, S., Diekötter, T., Boldt, L., Wolters, V., Dauber, J., 2012. Trait-specific effects of habitat isolation on carabid species richness and community composition in managed grasslands. Insect Conservation and Diversity 5, 9-18. 
882 Wardle, D.A., 2006. The influence of biotic interactions on soil biodiversity. Ecology Letters 9, 870-

1 2883 3 4 5 6 7 8 9 10 11 12 886.

Wright, T.E., Kasel, S., Tausz, M., Bennett, L.T., 2010. Edge microclimate of temperate woodlands as affected by adjoining land use. Agricultural and Forest Meteorology 150, 1138-1146.

886 Wu, J.G., Loucks, O.L., 1995. From balance of nature to hierarchical patch dynamics: a paradigm shift in ecology. Quarterly Review of Biology 70, 439-466. 


\section{FIGURE CAPTIONS}

2 Figure 1: Statistical diagram picturing steps of data analyses. Arrows represent effects of factors on

3 variables (collembolan diversity and soil properties). Direct effects are represented by continuous

4 arrows and indirect effects by dotted arrows. Model type 1 (arrow 1) stands for the linear models

5 testing the effect of the three habitat descriptors on collembolan diversity. Model type 2 (arrow 2)

6 stands for linear and generalized linear models testing the effect of the habitat descriptors on soil

7 physicochemical properties. Model type 3 (arrows 1 and 3) stands for linear models testing the effects

8 of the three habitat descriptors and a soil property on diversity indicators.

$9 \quad$ Figure 2: Individual based rarefaction curves old forests (F_old), recent forests (F_rec), old agricultural land (A_old) and recent agricultural land (A_rec).

Figure 3: Mean species density (3a), Shannon index (3b) and species richness (3c) of old (grey) and recent (white) agricultural and forest habitats. Letters indicate significant differences among means. "A" and "B" labels represent significant differences between agricultural and forest habitats. Stars show simple effect of age $\left(\mathrm{p}<0.05^{*} ; \mathrm{p}<0.01^{* *} ; \mathrm{p}<0.001^{* * *}\right)$. Error bars represent standard errors.

Figure 4: Mean species density (4a) and species richness (4b) according to Habitat Type, Temporal Continuity (two age classes: old and recent) and Spatial Isolation (three classes: 0 black bars. 1 white bars and 2 grey bars). Error bars represent standard errors.

Figure 5: Correlation coefficients (Pearson) between species density (grey bars), species richness (dashed bars) or Shannon index (white bars) and soil properties for the complete data set (agricultural land and forest) (5a) and for forest only (5b). Soil pH: $\mathrm{pH}$, total nitrogen content: Ntot, total carbon content: Ctot, carbon to nitrogen ration: $\mathrm{CN}$, bioavailable phosphorus: $\mathrm{Ph}$, cation exchange capacity: CEC, soil moisture: moist, soil density: dens and Humus Index: Humus. Stars show significant correlation $\left(\mathrm{p}<0.05^{*} ; \mathrm{p}<0.01^{* *} ; \mathrm{p}<0.001^{* * *}\right)$ between species density, species richness or Shannon index and each soil parameters listed above.

Figure 6: Least square means for species density and species richness obtained using the model testing for the effect of the three habitat descriptors as well as total carbon on species density and species richness. Least square means for species density are represented according to Habitat Type (agricultural, grey bars and forested, white bars) and Spatial Isolation (three isolation classes 0, 1 and 
29 2) (6a), and least square means for species density and species richness are represented according to

30 Temporal Continuity (two age classes: old, dashed bars and recent, white bars) and Spatial Isolation

31 (three isolation classes 0,1 and 2) (respectively 6b and 6c). Error bars represent standard errors. Stars

32 show significant differences between habitat types (6a) or ages (6b and $6 \mathrm{c}$ ) within each isolation class. 
Habitat Spatial and Temporal Continuity

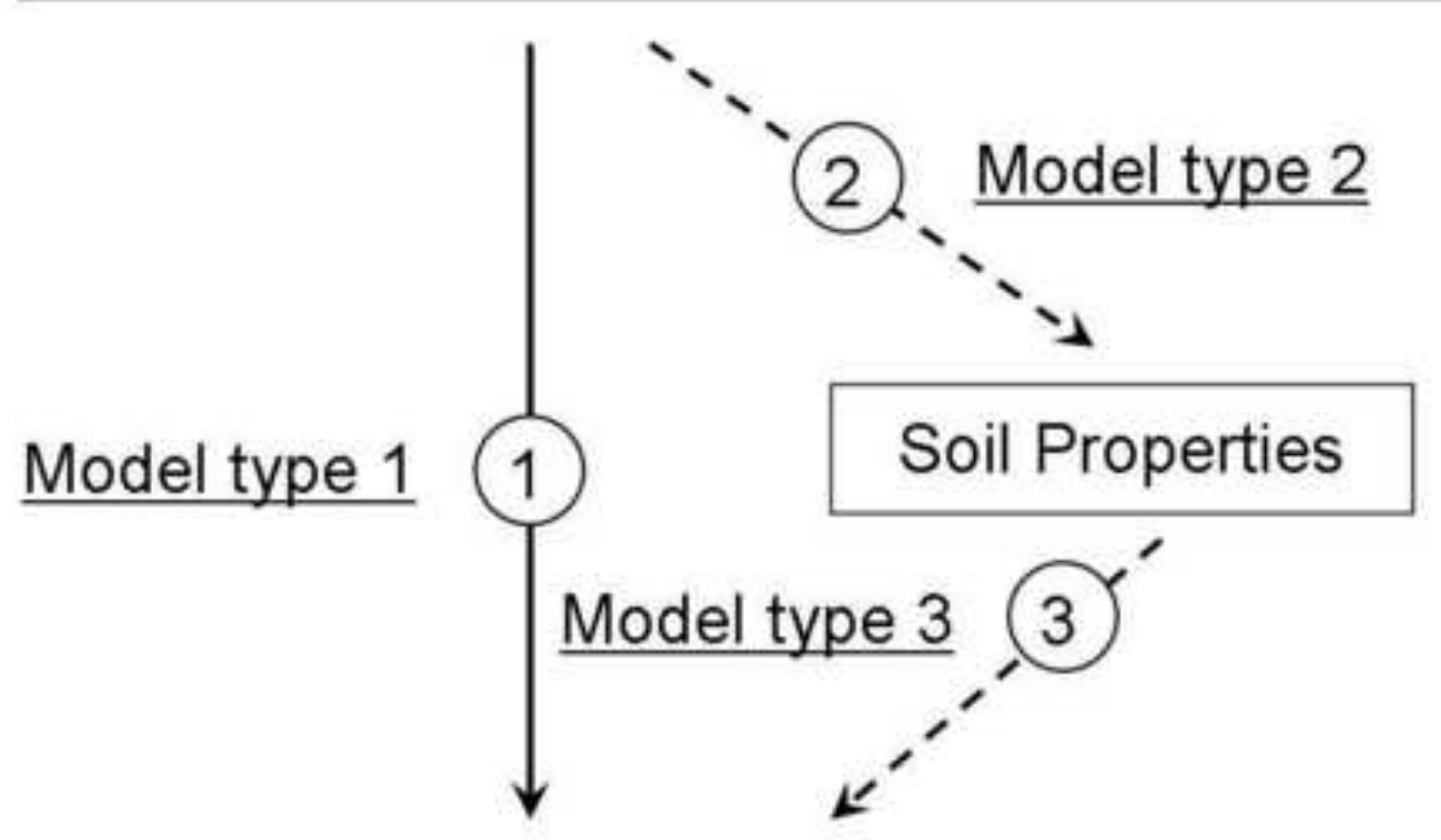

\section{Direct effects}

\section{Indirect effects}

Biodiversity of Collembola 


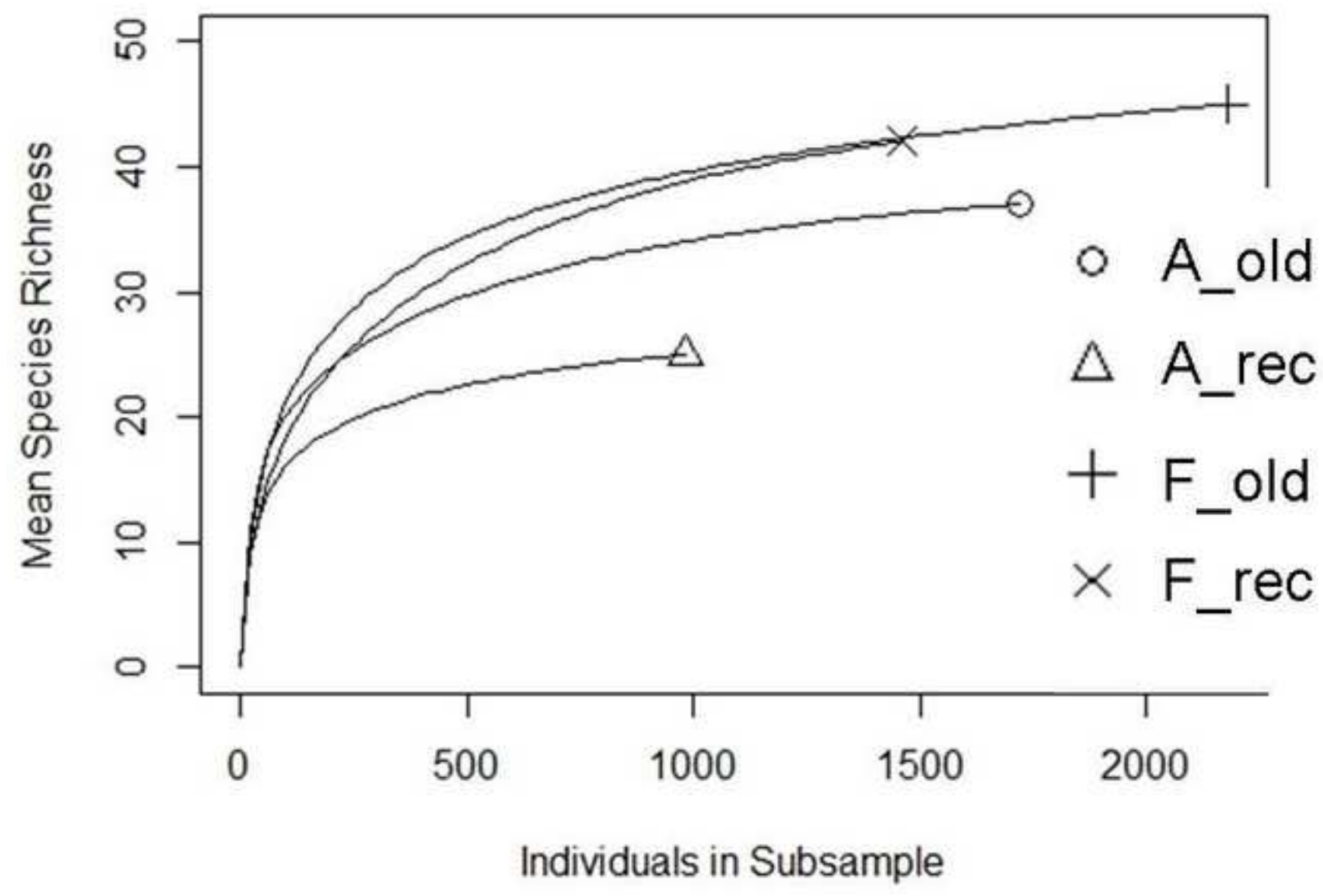


a)

b)
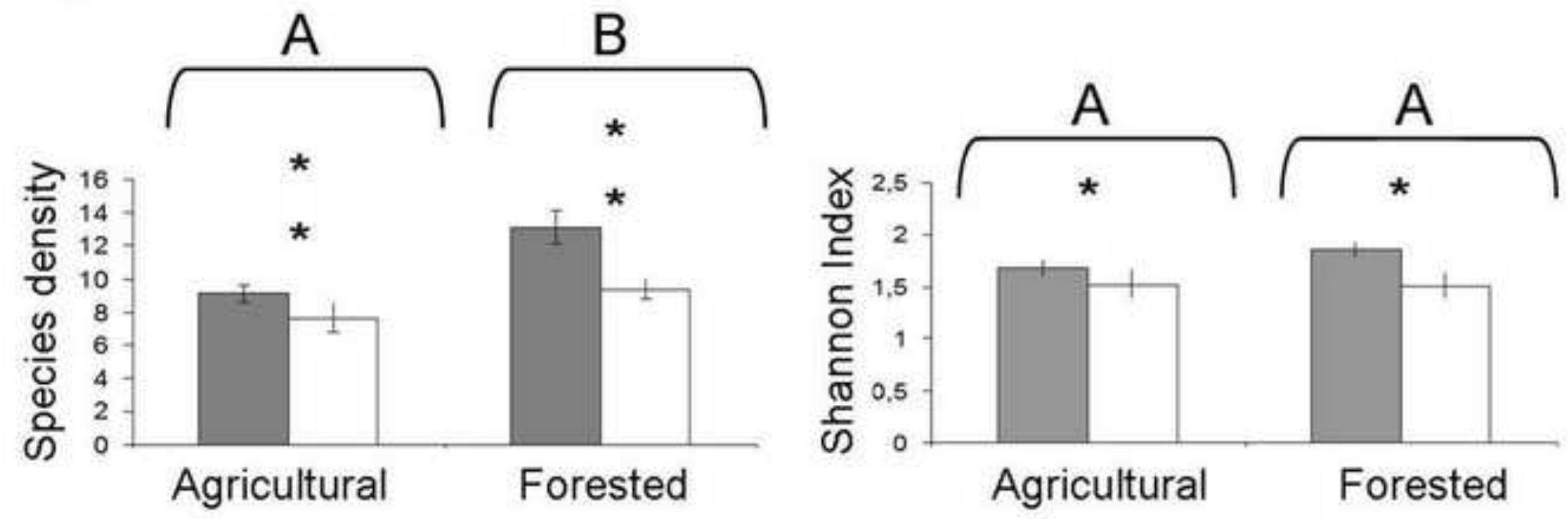

c)

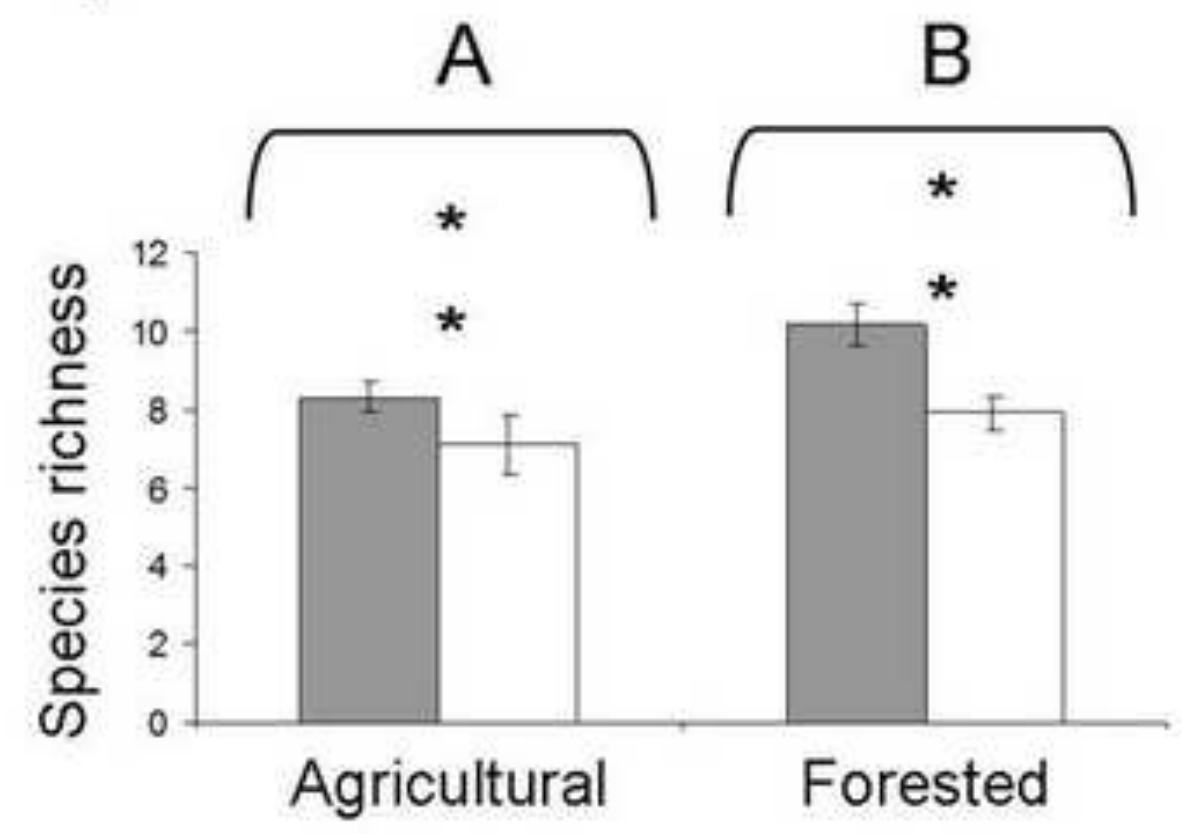

$\square$ Old

$\square$ Recent Agricultural Forested 

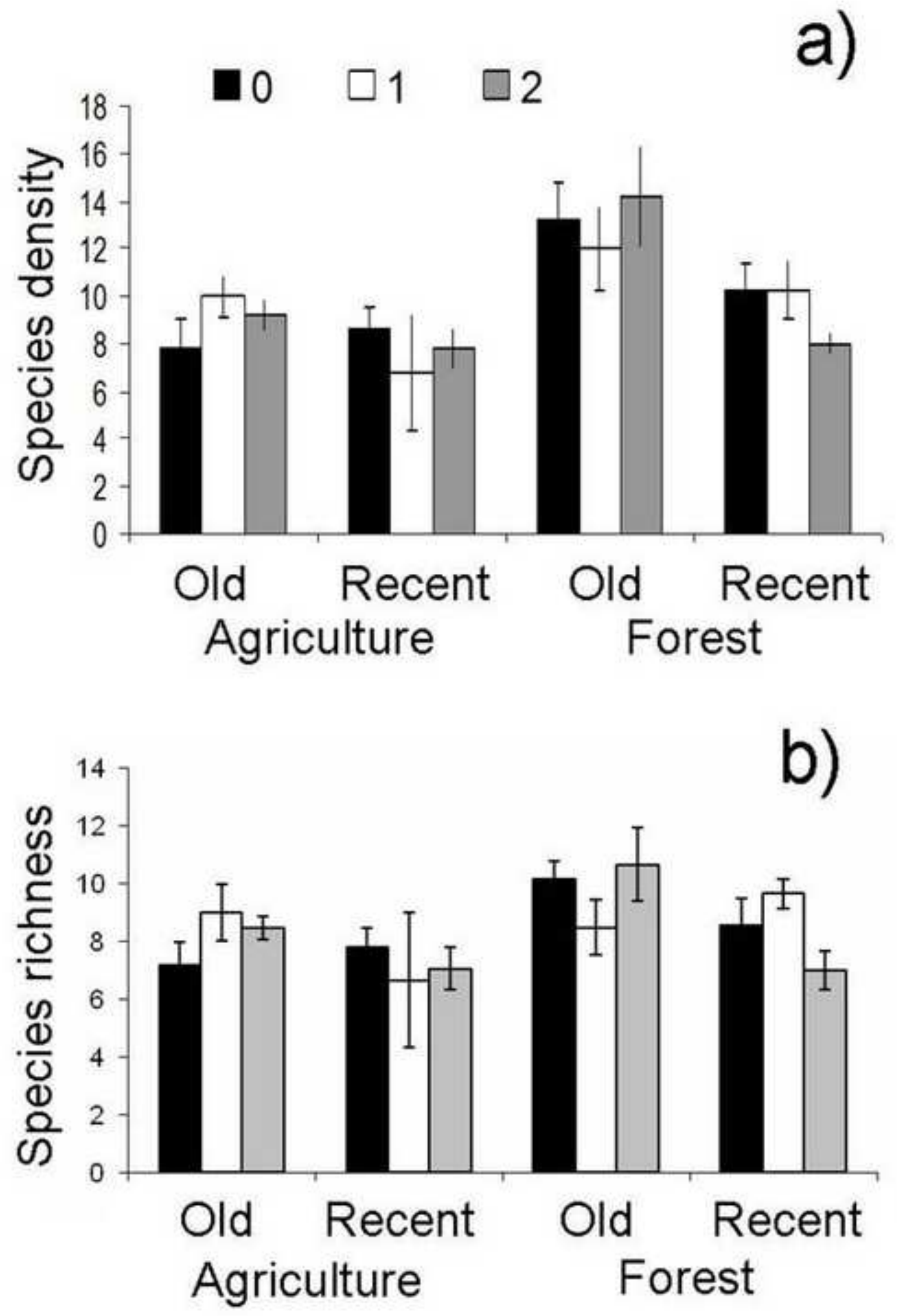


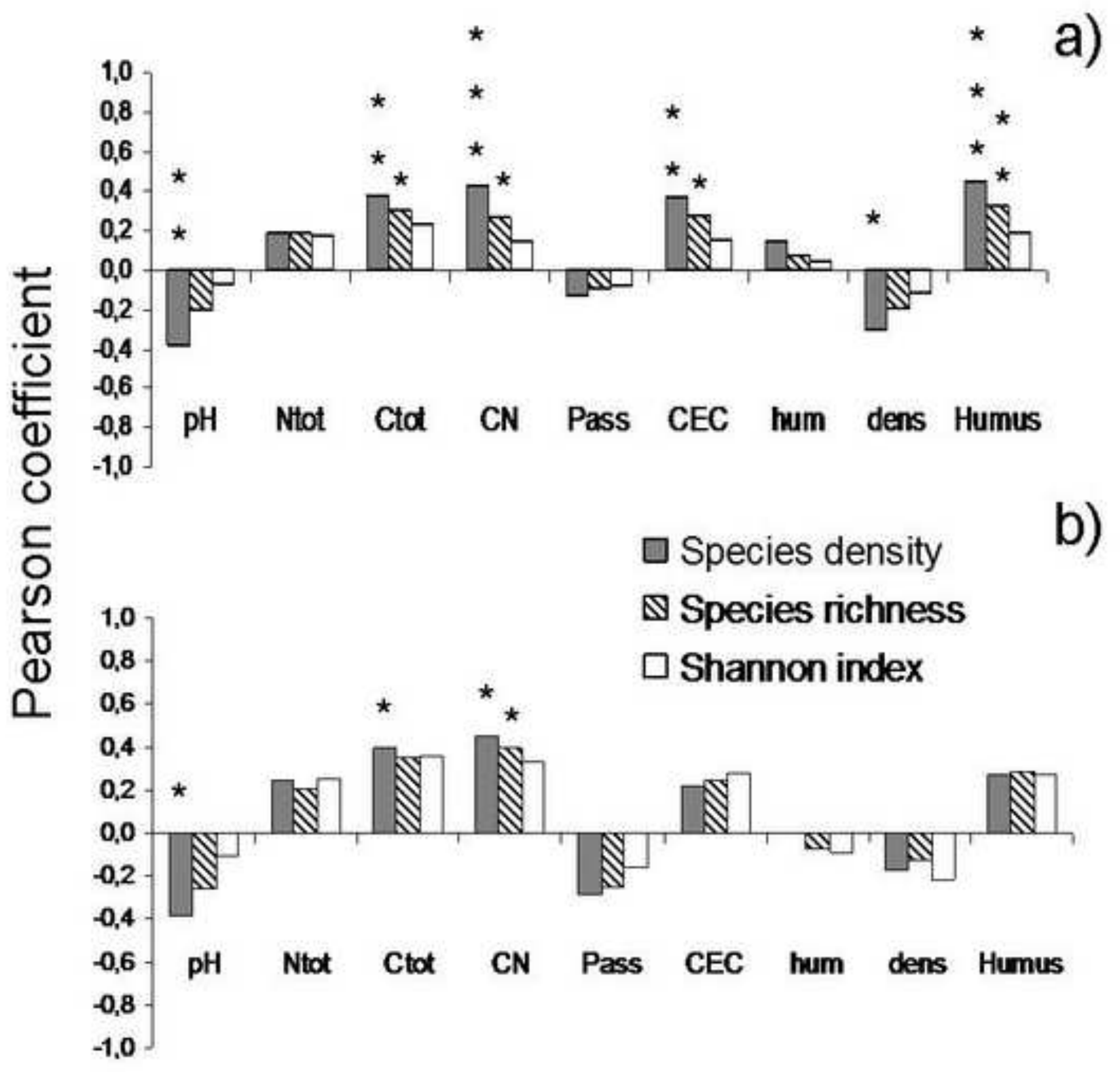



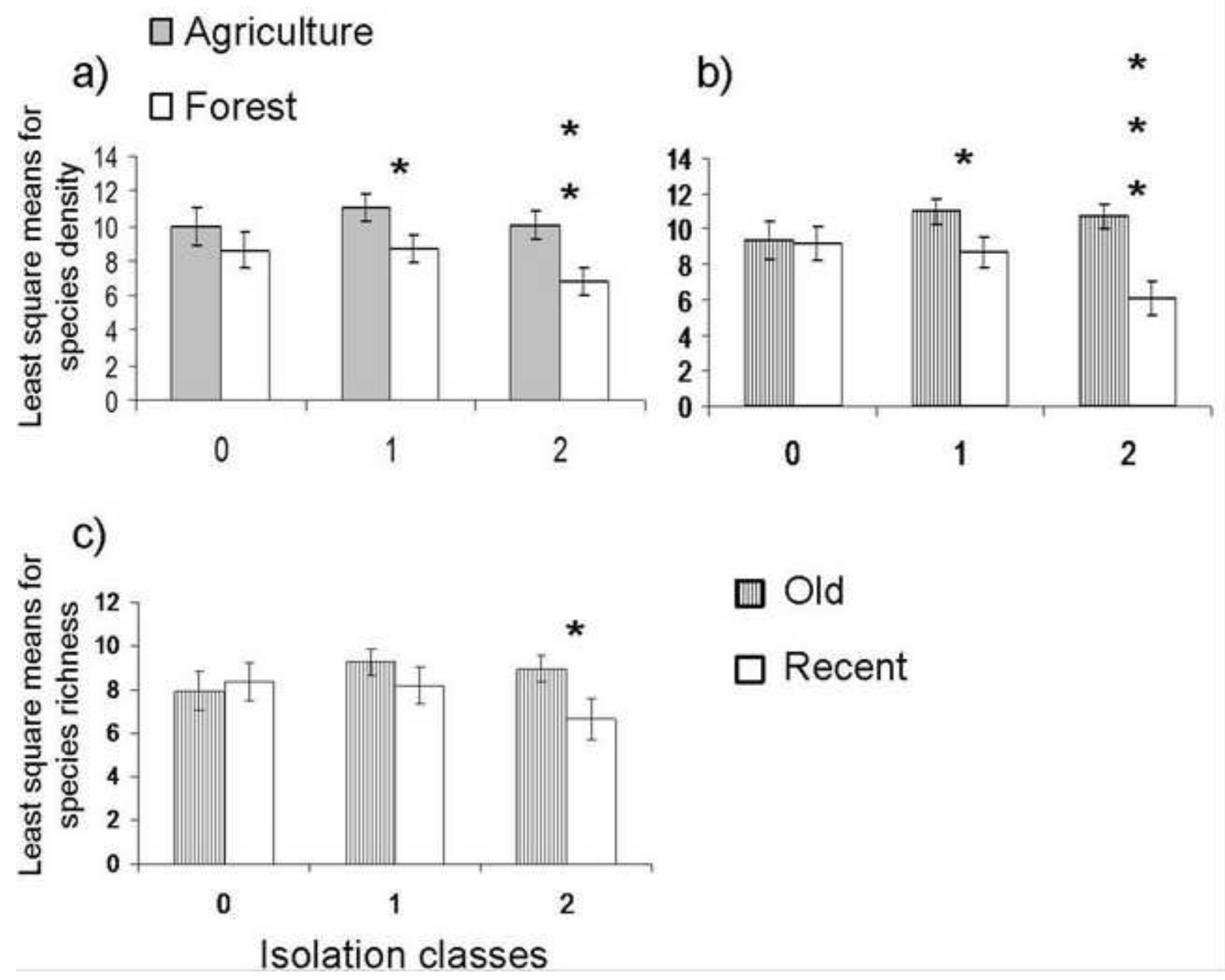
1 Table 1. Effect of habitat descriptors (Habitat Type HT, Temporal Continuity TC and Spatial Isolation

2 SI) and all their interactions on Collembola diversity indicators (Species density $=$ total number of

3 species collected in a sample of $0.2 \mathrm{dm}^{2}$, Rarefied species richness $=$ number of species estimated for

457 individuals, Shannon index, Dominance $=$ relative frequency of most abundant species, Abundance

$5=$ total number of individuals per sample). Transformation used on and results of linear models ( $\mathrm{F}$

6 value and degrees of freedom df). Significance levels: $p<0.05^{*} ; \mathrm{p}<0.01^{* *} ; \mathrm{p}<0.001 * * *$.

7

\begin{tabular}{|c|c|c|c|c|c|c|}
\hline & & & & F value & & \\
\hline & $\mathrm{df}$ & $\begin{array}{l}\text { Species } \\
\text { density }\end{array}$ & $\begin{array}{l}\text { Species } \\
\text { richness }\end{array}$ & $\begin{array}{l}\text { Shannon } \\
\text { Index }\end{array}$ & Dominance & Abundance \\
\hline Habitat type (HT) & 1 & $14.2 * * *$ & $0.01 *$ & 0.54 & 0.83 & $7.09 *$ \\
\hline Temporal Continuity (TC) & 1 & $9.84 * *$ & $0.006 * *$ & $5.23 *$ & 0.36 & 0.99 \\
\hline Spatial Isolation (SI) & 2 & 0.03 & 0.97 & 0.23 & 0.17 & 0.15 \\
\hline $\mathrm{HT}: \mathrm{TC}$ & 1 & 2.29 & 0.33 & 0.97 & 0.17 & 0.71 \\
\hline HT : SI & 2 & 0.12 & 0.84 & 0.22 & 0.17 & 0.55 \\
\hline TC : SI & 2 & 1.06 & 0.34 & 0.44 & 0.14 & 0.25 \\
\hline $\mathrm{HT}: \mathrm{TC}: \mathrm{SI}$ & 2 & 1.60 & 0.36 & 1.20 & 0.52 & 1.75 \\
\hline $\mathrm{R}^{2}$ & & 0.40 & 0.30 & 0.18 & 0.06 & 0.23 \\
\hline Transformation & & none & none & none & $\log _{10}$ & none \\
\hline
\end{tabular}

8 
9 Table 2. Soil characteristics (mean values and standard deviations) showing differences between

10 agricultural and forest habitats. Total carbon content (Ctot), soil $\mathrm{pH}(\mathrm{pH})$, carbon to nitrogen ratio

$11(\mathrm{C} / \mathrm{N})$, cation exchange capacity (CEC), soil moisture (Moisture), bulk density (Density) and Humus

12 index (Humus). Significance levels: p-values correspond to results of linear and generalized linear

13 models presented in Table $3\left(\mathrm{p}<0.05^{*} ; \mathrm{p}<0.01^{* * ;} ; \mathrm{p}<0.001^{* * *}\right)$.

14

15

16

17

18

19

20

21

22

\begin{tabular}{llll}
\hline & Agriculture & Forest & p-value \\
\hline Ctot (\%) & $6.9 \pm 2.41$ & $8.74 \pm 3.87$ & $*$ \\
$\mathrm{pH}$ & $5.14 \pm 0.4$ & $3.95 \pm 0.39$ & $* * *$ \\
$\mathrm{C} / \mathrm{N}$ & $12.55 \pm 1.46$ & $15.88 \pm 2.88$ & $* * *$ \\
$\mathrm{CEC}(\mathrm{meq} \%)$ & $24.96 \pm 3.82$ & $36.57 \pm 8.91$ & $* * *$ \\
Moisture (\%) & $21.66 \pm 14.37$ & $28.78 \pm 14.98$ & $*$ \\
Density $\left(\mathrm{g} / \mathrm{cm}^{3}\right)$ & $0.9 \pm 0.22$ & $0.68 \pm 0.22$ & $* * *$ \\
Humus Index & $1 \pm 0$ & $3.54 \pm 1.55$ & $* * *$
\end{tabular}


Table 3. Effect of habitat descriptors (Habitat Type HT, Temporal Continuity TC and Spatial Isolation

24 SI) and all their interactions on soil properties. Soil $\mathrm{pH}(\mathrm{pH})$, total carbon content (Ctot), total nitrogen

25 content (Ntot), carbon to nitrogen ratio $(\mathrm{C} / \mathrm{N})$, bioavailable phosphorus (Phosphorus), cation exchange

26 capacity (CEC), soil moisture (Moisture), bulk density (Density) and Humus index (Humus).

27 Transformation, model type (distribution) and results of linear or generalized linear models (F

28 value/Chi square and degrees of freedom df). Significance levels: $p<0.05^{*} ; p<0.01^{* * ;} ;<0.001^{* * *}$.

\begin{tabular}{|c|c|c|c|c|c|c|c|c|c|c|}
\hline & \multicolumn{10}{|c|}{ F / Chi square } \\
\hline & $\mathrm{df}$ & $\mathrm{pH}$ & Ctot & Ntot & $\mathrm{C} / \mathrm{N}$ & Phosphorus & CEC & Moisture & Density & Humus \\
\hline Habitat type & 1 & $185.77 * * *$ & $4.85^{*}$ & 0.12 & $68.45 * * *$ & 2.74 & $47.42 * * *$ & $4.13^{*}$ & $13.66^{* * *}$ & $39.56^{* * *}$ \\
\hline Temporal Continuity & 1 & 2.34 & 2.16 & 1.05 & $9.43 * *$ & 0.32 & 0.19 & 0.08 & 0.04 & 0.37 \\
\hline Spatial Isolation & 2 & $6.28 * *$ & 0.10 & 0.42 & $6.07 * *$ & $3.74 *$ & 0.11 & 0.08 & 0.54 & 0.51 \\
\hline HT : TC & 1 & 2.53 & 0.07 & 0.86 & $27.86^{* * *}$ & 2.69 & 0.72 & 2.69 & 1.14 & 0.36 \\
\hline HT : SI & 2 & $5.60 * *$ & 1.47 & 1.62 & $5.27 * *$ & 2.94 & 1.68 & 0.66 & 1.27 & 0.51 \\
\hline $\mathrm{TC}: \mathrm{SI}$ & 2 & 1.34 & 1.12 & 1.51 & 1.27 & 2.92 & 0.63 & 0.25 & 0.21 & 0.21 \\
\hline HT : TC : SI & 2 & 2.74 & 1.99 & 0.70 & $5.69 * *$ & 0.85 & 0.90 & 0.27 & 0.78 & 0.21 \\
\hline $\mathrm{R}^{2}$ & & 0.82 & 0.26 & 0.12 & 0.77 & 0.35 & 0.55 & 0.12 & 0.28 & 0.63 \\
\hline Model type (distribution) & & Normal & Gamma & Gamma & Normal & Normal & Normal & Gamma & Gamma & Poisson \\
\hline Transformation & & none & none & none & none & $\log _{10}$ & $\log _{10}$ & none & none & none \\
\hline
\end{tabular}

29 
Table 4. Effect of habitat descriptors (Habitat Type HT, Temporal Continuity TC and Spatial Isolation SI), total soil carbon content (Ctot) (left hand side), soil $\mathrm{pH}$ (right hand side) and all their interactions on species density and species richness. Transformation and results of linear models ( $\mathrm{F}$ values and degrees of freedom df), tested after variable selection based on AIC criterion). Significance levels: $\mathrm{p}<0.05^{*} ; \mathrm{p}<0.01^{* *} ; \mathrm{p}<0.001 * * *$.

\begin{tabular}{|c|c|c|c|c|c|c|c|}
\hline \multicolumn{4}{|l|}{ Ctot model } & \multicolumn{4}{|l|}{ Soil pH model } \\
\hline & & Species & Species & & & Species & Species \\
\hline & & density & richness & & & density & richness \\
\hline & $\mathrm{df}$ & F value & F value & \multicolumn{4}{|c|}{$\mathrm{df}$} \\
\hline Habitat type (HT) & 1 & 0.79 & 0.15 & Habitat type (HT) & 1 & $5.98^{*}$ & 1.38 \\
\hline Temporal Continuity (TC) & 1 & 1.9 & 0.05 & Temporal Continuity (TC) & 1 & $6.00^{*}$ & $6.56^{*}$ \\
\hline Spatial Isolation (SI) & 2 & 0.2 & 0.02 & Spatial Isolation (SI) & 2 & 0.33 & 3.07 \\
\hline Total Carbon (Ctot) & 1 & 0.00 & 0.66 & $\mathrm{pH} \mathrm{H}_{2} \mathrm{O}(\mathrm{pH})$ & 1 & 0.02 & 0.64 \\
\hline HT : TC & 1 & l & 2.36 & HT : TC & 1 & $4.4^{*}$ & 2.34 \\
\hline HT : SI & 2 & $4.14^{*}$ & 2.14 & HT : SI & 2 & $4.56^{*}$ & 1.80 \\
\hline TC $:$ SI & 2 & $10.13^{* * *}$ & $5.28 * *$ & TC : SI & 2 & $4.04 *$ & 1.73 \\
\hline HT : Ctot & 1 & $4.62^{*}$ & 0.02 & $\mathrm{HT}: \mathrm{pH}$ & 1 & $5.23^{*}$ & 0.92 \\
\hline TC : Ctot & 1 & $6.00^{*}$ & 0.03 & $\mathrm{TC}: \mathrm{pH}$ & 1 & $9.84 * *$ & $5.65^{*}$ \\
\hline SI : Ctot & 2 & 0.07 & 0.07 & $\mathrm{SI}: \mathrm{pH}$ & 2 & $4.89^{*}$ & 2.69 \\
\hline HT : TC : Ctot & 1 & I & 2.07 & $\mathrm{HT}: \mathrm{TC}: \mathrm{pH}$ & 2 & 3.2 & I \\
\hline HT : SI : Ctot & 2 & $5.04 *$ & 2.31 & $\mathrm{HT}: \mathrm{SI}: \mathrm{pH}$ & 1 & 2.56 & 1.59 \\
\hline TC : SI : Ctot & 2 & $11.34 * * *$ & $5.74 * *$ & & & & \\
\hline $\mathrm{R}^{2}$ & & 0.67 & 0.49 & $\overline{\mathrm{R}^{2}}$ & & 0.62 & 0.49 \\
\hline Transformation & & none & none & Transformation & & none & none \\
\hline
\end{tabular}


Appendix A. List of study sites with their classification according to habitat type (agriculture vs forest), temporal continuity (oldt vs recent) and spatial isolation (three isolation classes), followed by \% edge contrast with opposite habitat type, matrice type (old or recent or mixed), station code, land use, humus form according to Brêthes et al. (1995) and main community indices of Collembola (total abundance per sample, species density, species richness, Shannon index and dominance). The edge contrast is the \% borderline which the patch with the sampling point shares with the opposite habitat in the circle of $300 \mathrm{~m}$ arround the sampling point. The matrix type is the dominant age of the habitat surrounding the patch with the sampling point. The combinaison of both defines the level of isolation.

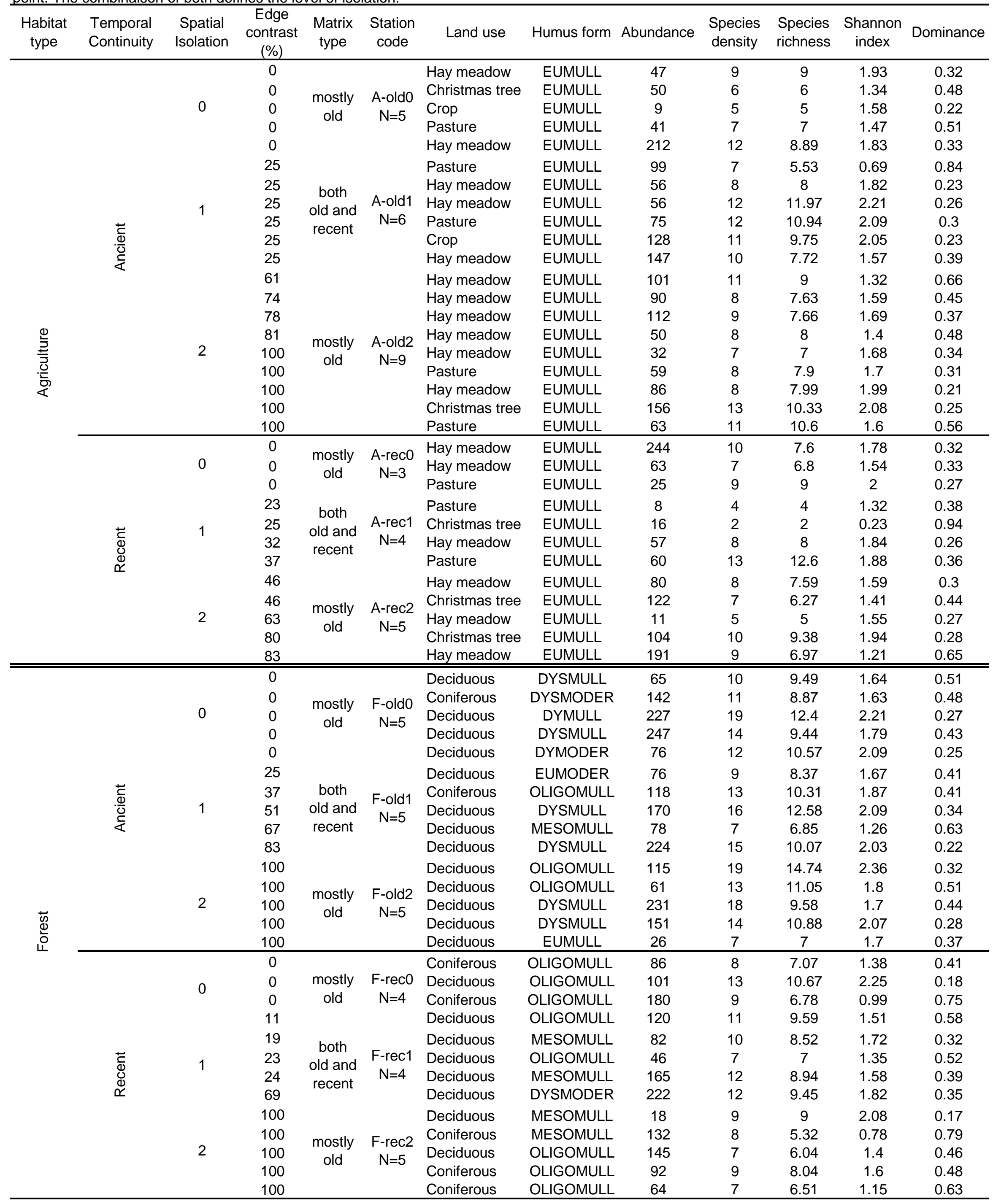


Appendix B. List of collembolan species in the 60 studied samples, together with total abundance and frequency (number of samples where the species was present)

Species names

Abundance Frequency

Arropalithes pygmaeus

Brachystomella parvula

Ceratophysella armata

Ceratophysella denticulata

Cryptopygus scapelliferus

Desoria violacea

Detriturus jubilarius

Deuteraphorura inermis

Deuterosminthurus pallipes

Entomobrya nivalis

Folsomia candida

Folsomia fimetaria

Folsomia listeri

Folsomia manolachei

Folsomia quadrioculata

Folsomia spinosa

Friesea claviseta

Friesea mirabilis

Friesea truncata

Heteromurus nitidus

Hypogastrura assimilis

Isotoma antennalis

Isotomurus fuscus

Isotomiella minor

Isotomurus palustris

Isotomiella paraminor

Isotomodes productus

Isotomodes trisetosus

Isotoma viridis

Lepidocyrtus cyaneus

Lepidocyrtus lanuginosus

Lepidocyrtus lignorum

Lipothrix lubbocki

Megalothorax minimus

Mesaphorura critica

Mesaphorura krausbaueri

Mesaphorura macrochaeta

Mesaphorura sp.

Mesaphorura sylvatica

Mesaphorura yosii

Micraphorura absoloni

Micranurida pygmaea

Micranurida sensillata

Neanura muscorum

Neotullbergia ramicuspis

Odontella lamellifera

Orchesella cincta

Orchesella sp.

Paratullbergia callipygos

Parisotoma notabilis

Protaphorura armata

Pseudosinella alba

Pseudanophorus binoculatus

Pseudosinella decipens

Pseudosinella mauli

Pseudachorutes parvulus

Sminthurinus aureus

Sminthurides schoett

Sminthurinus signatus

Sphaeridia pumilis

Stenaphorura lubbocki

Subisotoma pusilla

Tomocerus minutus

Willemia anophthalma

Willemia intermedia

Xenyllodes armatus

Xenylla corticalis

Xenylla grisea

Xenylla tullbergi

Xenylla xavieri

\begin{tabular}{|c|c|}
\hline 1 & 1 \\
\hline 29 & 11 \\
\hline 3 & 2 \\
\hline 49 & 8 \\
\hline 1 & 1 \\
\hline 108 & 1 \\
\hline 42 & 6 \\
\hline 53 & 7 \\
\hline 11 & 4 \\
\hline 4 & 1 \\
\hline 8 & 5 \\
\hline 4 & 3 \\
\hline 8 & 1 \\
\hline 1 & 1 \\
\hline 535 & 20 \\
\hline 694 & 31 \\
\hline 3 & 1 \\
\hline 6 & 1 \\
\hline 8 & 1 \\
\hline 351 & 32 \\
\hline 6 & 4 \\
\hline 83 & 1 \\
\hline 37 & 7 \\
\hline 583 & 37 \\
\hline 39 & 5 \\
\hline 75 & 6 \\
\hline 6 & 1 \\
\hline 1 & 1 \\
\hline 161 & 23 \\
\hline 125 & 22 \\
\hline 687 & 48 \\
\hline 195 & 17 \\
\hline 9 & 5 \\
\hline 48 & 16 \\
\hline 5 & 2 \\
\hline 19 & 5 \\
\hline 828 & 43 \\
\hline 14 & 3 \\
\hline 1 & 1 \\
\hline 76 & 7 \\
\hline 48 & 6 \\
\hline 22 & 8 \\
\hline 2 & 1 \\
\hline 11 & 1 \\
\hline 20 & 3 \\
\hline 5 & 1 \\
\hline 2 & 2 \\
\hline 12 & 4 \\
\hline 73 & 15 \\
\hline 650 & 42 \\
\hline 281 & 24 \\
\hline 27 & 8 \\
\hline 3 & 1 \\
\hline 2 & 1 \\
\hline 53 & 15 \\
\hline 10 & 3 \\
\hline 31 & 12 \\
\hline 10 & 3 \\
\hline 20 & 10 \\
\hline 72 & 19 \\
\hline 2 & 1 \\
\hline 1 & 1 \\
\hline 2 & 1 \\
\hline 3 & 2 \\
\hline 4 & 3 \\
\hline 3 & 2 \\
\hline 1 & 1 \\
\hline 7 & 3 \\
\hline 42 & 6 \\
\hline 3 & 2 \\
\hline
\end{tabular}

